\title{
Parallel and serial processes in the human oculomotor system: bimodal integration and express saccades
}

\author{
G. Nozawa ${ }^{1}$, P. A. Reuter-Lorenz ${ }^{2}$, H. C. Hughes ${ }^{1}$ \\ ${ }^{1}$ Department of Psychology, Dartmouth College, Hanover, NH 03755, USA \\ ${ }^{2}$ Department of Psychology, University of Michigan, Ann Arbor, MI 48104, USA
}

Received: 16 June 1993/Accepted in revised form: 23 June 1994

\begin{abstract}
Saccadic reaction times (SRTs) were analyzed in the context of stochastic models of information processing (e.g., Townsend and Ashby 1983) to reveal the processing architecture(s) underlying integrative interactions between visual and auditory inputs and the mechanisms of express saccades. The results support the following conclusions. Bimodal (visual + auditory) targets are processed in parallel, and facilitate SRT to an extent that exceeds levels attainable by probability summation. This strongly implies neural summation between elements responding to spatially aligned visual and auditory inputs in the human oculomotor system. Second, express saccades are produced within a separable processing stage that is organized in series with that responsible for intersensory integration. A model is developed that implements this combination of parallel and serial processing. The activity in parallel input channels is summed within a sensory stage which is organized in series with a pre-motor and motor stage. The time course of each subprocess is considered a random variable, and different experimental manipulations can selectively influence different stages. Parallels between the model and physiological data are explored.
\end{abstract}

\section{Introduction}

\section{I Identification of serial and parallel processes}

Since the pioneering work of Donders (1869), attempts have been made to study the time course and organization of elementary mental processes using reaction times (RTs) as a dependent measure. Following Donder's assumption of serially organized component processing stages, Sternberg (1969) developed what is known as additive factors logic. This method examines the effects of the factorial combination $\left\{\left(A_{\mathrm{L}}, B_{\mathrm{L}}\right),\left(A_{\mathrm{H}}, B_{\mathrm{L}}\right),\left(A_{\mathrm{L}}, B_{\mathrm{H}}\right)\right.$, $\left.\left(A_{\mathrm{H}}, B_{\mathrm{H}}\right)\right\}$ of two levels ( $\mathrm{L}_{\mathrm{L}}\{$ low $\}$ and ${ }_{\mathrm{H}}\{$ high $\}$ ) of two

Correspondence to: $\mathrm{H}$. C. Hughes experimental factors ( $A$ and $B$ ) on the mean RT. Additive factors logic assumes that (1) the component processes are serially organized and (2) each factor influences the duration of different processing stages (the assumption of selective influence, see Sternberg 1969; Townsend and Ashby 1983). Given these assumptions, we may conclude that $A$ and $B$ influence different, serially organized operations if factors $A$ and $B$ exert additive effects on the mean RT $(\overline{\mathrm{RT}})$. An illustration of such additivity is shown in Fig. $1 \mathrm{~A}$.

The results can be evaluated by analysis of variance (ANOVA), in which case additivity is indicated by significant main effects for factors $A$ and $B$, but no interaction. The interaction is equivalently expressed by the mean contrast, where the mean contrast is defined as follows:

$$
\begin{aligned}
\Delta_{A, B}^{2} \overline{\mathrm{RT}}(A, B)= & \overline{\mathrm{RT}}\left(A_{\mathrm{L}}, B_{\mathrm{L}}\right)-\overline{\mathrm{RT}}\left(A_{\mathrm{L}}, B_{\mathrm{H}}\right) \\
& -\overline{\operatorname{RT}}\left(A_{\mathrm{H}}, B_{\mathrm{L}}\right) \\
& +\overline{\operatorname{RT}}\left(A_{\mathrm{H}}, B_{\mathrm{H}}\right)
\end{aligned}
$$

The mean contrast is often referred to as the interaction contrast in statistics. In the case of additivity, $\Delta_{A, B}^{2} \overline{\mathrm{RT}}(A, B)=0$.

While additivity at the level of the mean RT provides strong evidence of serial processing (Sternberg 1969), an important issue arises when additivity is not obtained [i.e., there is a significant interaction term in the analysis of variance, or $\left.\Delta_{A, B}^{2} \overline{\mathrm{RT}}(A, B) \neq 0\right]$. According to additive factors logic, nonadditivity is generally taken to indicate failure of a selective influence (that at least one component process is influenced by both experimental factors). However, recent work by Townsend and collaborators (e.g., Nozawa 1989, 1992; Townsend and Piotrowski 1981; Townsend and Ashby 1983; Townsend 1984; Townsend and Nozawa, 1994, manuscript submitted) has shown that such interactions are also diagnostic of parallel processing.

Indeed, the sign of the mean contrast specifies the 'stopping rule' (the rule by which processing is terminated) in a parallel system. Consider the parallel architecture portrayed in Fig. 2A. Townsend and Ashby (1983) 


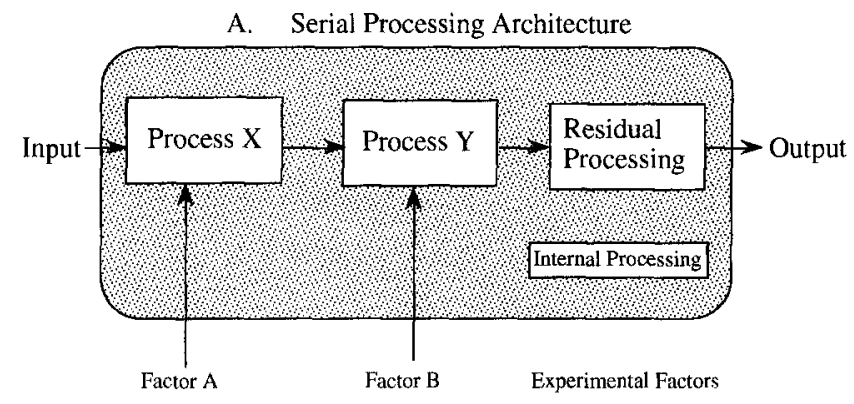

B. Additivity of Experimental Factors A and B

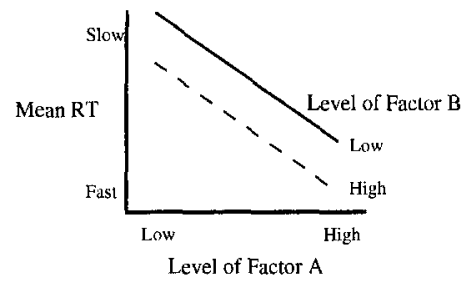

Fig. 1. A Schematic representation of a serial processing architecture. B Illustration of additivity implied by this serial information processing system. For this pattern of results, the mean contrast $=0$. See text for details

have shown that if a task requires complete processing in both parallel channels (exhaustive parallel processing), then the mean contrast in a factorial experiment will be less than 0 ('subadditive' interaction). Conversely, Townsend and Nozawa (1994, manuscript submitted) have shown that if a task can be performed on the basis of the first channel to complete its processing (parallel processing in the minimum completion mode, as is the case for the OR operator in Fig. 2A), then the mean contrast is positive ('superadditive' interaction).

Here we shall only be concerned with the minimum completion mode of parallel processing. To illustrate the logic that underlies these concepts, duplication of the proof that parallel processing in the minimum completion mode produces a superadditive mean contrast is provided in Appendix 1. More complete treatments are found in Townsend and Nozawa (1994, manuscript submitted).

\subsection{Parallel processing in the minimum completion mode: race versus summation models}

Parallel processing in the minimum completion mode is well-suited to perform tasks in which the same response can be initiated upon detecting any one of several different signals. A specific case of this type of experiment is often termed the redundant targets paradigm, in which subjects must respond to the presentation of target $A$, target $B$ or target $[A$ and $B$ ]. If $A$ and $B$ are processed in parallel, the stimulus-response mapping can be likened to the logical operation of a boolean OR gate (Fig. 2A) since a response can be initiated as soon as processing of either target is completed. Such a system is expected to show a benefit from the presentation of multiple targets over the level of performance obtained from single-target
A. Parallel Processing Architecture

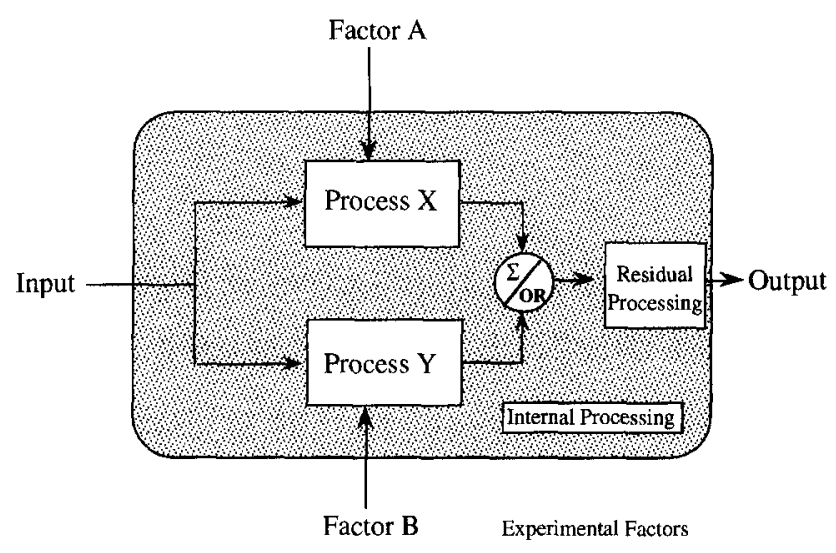

B. Superadditivity of Experimental Factors A and B

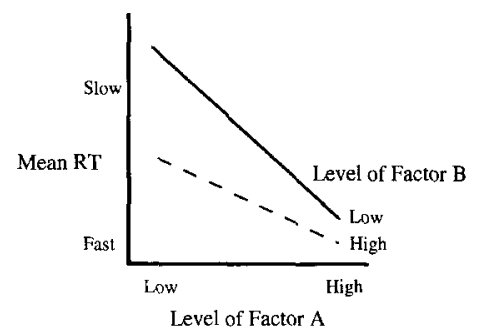

Fig. 2. A Schematic representation of a parallel processing architecture. B Illustration of superadditivity implied by both parallel processing in the the minimum completion mode $(O R)$ and neural summation $(\Sigma)$. For this pattern of results, the mean contrast $>0$. See text for details

presentations, and redundancy gains are frequently observed (e.g., Miller 1982, 1986; Raab 1962; Westendorf and Blake 1988).

Redundancy gains need not imply facilitatory interactions between parallel channels, however. Consider a parallel system operating in the minimum completion mode. We assume that the time course associated with the processing in each channel is a random variable $\left(T_{A}\right.$ and $T_{B}$ ). We also assume that the processes associated with response execution are relatively constant, such that in any given trial, the observed RT is determined by the minimum of $T_{A}$ and $T_{B}\left(\min \left[T_{A}, T_{B}\right]\right)$. Redundancy gains are expected since

$E\left(\min \left[T_{A}, T_{B}\right]\right) \leqslant \min \left[E\left(T_{A}\right), E\left(T_{B}\right)\right]$

The above expression is known as Jensen's inequality (see p. 197 of Dudewicz 1976). Thus, redundancy gains can be a simple consequence of a minimum operator applied to the probability densities of $T_{A}$ and $T_{B}$. Such models of redundant target effects are often called race models.

\subsubsection{Predicted performance according to the race model.} If (1) the processing times associated with each input are stochastically independent and (2) are not influenced by target processing on other channels (i.e., selective influence holds), then we can express the probability that 
either channel has completed its processing by a given time $t$ as

$$
\begin{aligned}
P\left(\min \left[T_{A}, T_{B}\right] \leqslant t\right)= & P\left(T_{A} \leqslant t \cup T_{B} \leqslant t\right) \\
= & P\left(T_{A} \leqslant t\right)+P\left(T_{B} \leqslant t\right) \\
& -P\left(T_{A} \leqslant t \cap T_{B} \leqslant t\right) \\
= & P\left(T_{A} \leqslant t\right)+P\left(T_{B} \leqslant t\right) \\
& -\left(P\left(T_{A} \leqslant t\right) \times P\left(T_{B} \leqslant t\right)\right)
\end{aligned}
$$

If we rewrite the above expression in terms of overall reaction times, we have an estimate of the level of performance predicted by the independent race model:

$$
\begin{aligned}
P\left(\mathrm{RT}_{A \& B}^{\text {Predicted }} \leqslant t\right)= & P\left(\mathrm{RT}_{A} \leqslant t\right)+P\left(\mathrm{RT}_{B} \leqslant t\right) \\
& -\left(P\left(\mathrm{RT}_{A} \leqslant t\right) \times P\left(\mathrm{RT}_{B} \leqslant t\right)\right)
\end{aligned}
$$

where $P\left(\mathrm{RT}_{A} \leqslant t\right)$ is the cumulative distribution function (CDF) of the RTs to target $A, P\left(\mathrm{RT}_{B} \leqslant t\right)$ is the CDF to target $B$, and $P\left(\mathrm{RT}_{A \& B}^{\text {Predicted }} \leqslant t\right)$ is the predicted CDF of RTs to the redundant targets.

Notice that $P\left(T_{A} \leqslant t \cap T_{B} \leqslant t\right)=P\left(T_{A} \leqslant t\right)$ $\times P\left(T_{B} \leqslant t\right)$ if and only if $T_{A}$ and $T_{B}$ are stochastically independent. If $T_{A}$ and $T_{B}$ are positively dependent, then $P\left(T_{A} \leqslant t \cap T_{B} \leqslant t\right)>P\left(T_{A} \leqslant t\right) \times P\left(T_{B} \leqslant t\right)$; if they are negatively dependent, then $P\left(T_{A} \leqslant t \cap T_{B} \leqslant t\right)<$ $P\left(T_{A} \leqslant t\right) \times P\left(T_{B} \leqslant t\right)$. Thus, stochastic dependencies between the processing times for each target alter the level of performance predicted by probability summation in a redundant target task; relative to an independent race (4), negative dependencies will reduce RTs, and positive dependencies will increase them.

1.2.2 Predicting performance of neural summation models. Neural summation (or coactivation) models suggest a fundamentally different architecture. Neural summation models posit that the activities (i.e., the neural activities) associated with the processing in each channel are summed prior to a single decision stage. Both race models and neural summation models invoke parallel processing, both predict superadditivity of the mean contrast, and both predict redundancy gains. How then can they be distinguished? In general, the answer lies in the fact that neural summation models predict larger redundancy gains than race models.

Miller (1982) pointed out that all race models can be rejected if the obtained redundant target CDF at any point exceeds the sum of the single target CDFs. The logic is as follows. Regardless of the dependent structure between $T_{A}$ and $T_{B}$, the joint probability, $P\left(T_{A} \leqslant t \cap T_{B} \leqslant t\right)$ lies in the interval between 0 and 1 . The most conservative estimate of redundant target performance according to a race model assumes that $P\left(T_{A} \leqslant t \cap T_{B} \leqslant t\right)=0$. Thus, all race models predict that

$P\left(\mathrm{RT}_{A \& B} \leqslant t\right) \leqslant P\left(\mathrm{RT}_{A} \leqslant t\right)+P\left(\mathrm{RT}_{B} \leqslant t\right)$

We refer to (5) as the race inequality, and violations of this equality provide strong evidence against race models (and by default, evidence favoring neural summation; e.g., Miller 1982; Colonius 1990). We now describe application of these methods to an analysis of latencies of saccadic eye movements.

\subsection{Applications of factorial methods to human oculomotor performance}

1.3.1 A case of serial processing: express saccades. As with other sensorimotor systems, SRTs decrease monotonically with increasing target intensity (e.g., Wheeless et al. 1967; Hughes and Kelsey 1984). In addition, however, SRTs are dramatically reduced simply by extinguishing the fixation stimulus prior to the presentation of the target (e.g., Boch and Fischer 1983; Fischer and Ramsperger 1984, 1986; Saslow 1967). This 'gap paradigm' has established that humans can generate accurate, visually guided saccades with latencies as short as $100 \mathrm{~ms}$ (Fischer and Ramsperger 1984; Fischer and Boch 1983; Reuter-Lorenz et al. 1991; Saslow 1967). Boch and Fischer (1983) have termed these 100-ms responses express saccades; they are probably the fastest visually guided movements humans are capable of producing.

Reuter-Lorenz et al. (1991) sought to determine whether target luminance and the facilitatory effects of the gap paradigm would exert interactive or additive effects on saccade latency. In contrast to predictions of an earlier model of express saccades (Reulen 1984a, b), Reuter-Lorenz et al. (1991) found clear evidence of additivity; the implication is that target luminance and fixation point offsets selectively influence separable, serially organized processing stages.

Additional evidence that the gap effect has little to do with enhanced visual processing per se was provided by Fendrich et al. (1991), who showed that fixation point offsets facilitate saccades to acoustic as well as visual targets. Further, Reuter-Lorenz et al. (1991) found that the gap effect was specific for saccades to an eccentric target; fixation point offsets did not facilitate manual responses or saccades directed away from an eccentric target (anti-saccades, see Hallet 1978). Similar findings were obtained in a subsequent experiment (ReuterLorenz et al. 1995). Although Iwasaki (1990) reported a modest gap effect using choice manual RTs, these effects were accompanied by substantial reductions in accuracy (whereas the more substantial facilitatory effects on saccades were not).

These findings of response specificity suggest that fixation point offsets preferentially influence a subprocess that is specific to the generation of goal-directed saccades, and this process probably follows sensory encoding of the target (serial architecture). Noting that the thresholds for eliciting a saccade by electrical stimulation are reduced following fixation point offsets (Goldberg et al. 1986), Reuter-Lorenz et al. (1991) suggested that removal of the fixation stimulus facilitated a transition within the oculomotor system from a fixation mode to a saccadic mode. We refer to this facilitatory effect as 'fixation release'. Fischer (1987) also considered the fact that active, fixation-related processes must be terminated before a saccade can be initiated. The position we 
Parallel-Serial Model

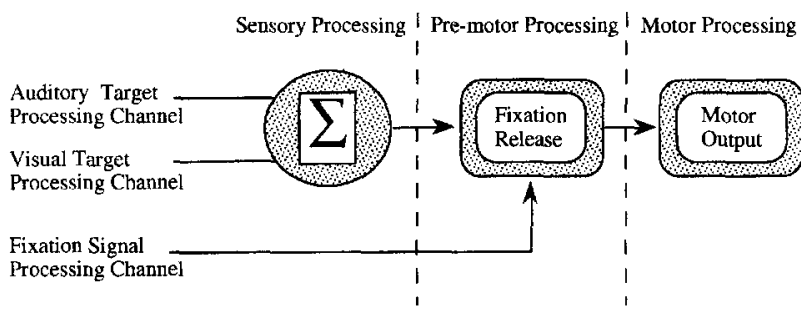

Fig. 3. Schematic representation of a two-stage model designed to account for bimodal interactions and express saccades

describe here is in some ways similar, but differs in that no special role of central attentive mechanisms is invoked. Various positions on the relationship between attentive states and express saccades can be found in a recent article by Fischer and Weber (1993) and related commentary.

1.3.2 A case of parallel processing: bimodal integration. Motivated by the electrophysiological findings of multimodal convergence within the oculomotor pathways (Jay and Sparks 1987; Meredith and Stein 1983; Peck 1987), Hughes et al. (1994) sought to determine the nature of auditory-visual interactions in human saccadic performance. Using a version of the redundant targets paradigm, Hughes et al. (1994) observed consistent violations of the race model inequality (5), suggesting neural summation between parallel auditory and visual inputs prior to the generation of saccades.

1.3.3 Test of the serial-parallel hypothesis. Taken together, these results suggest the hypothesis illustrated in Fig. 3. Parallel auditory and visual channels provide inputs to a summation stage, whose output is transmitted to a pre-motor stage. The time course of the pre-motor stage is influenced by a fixation signal. Active fixation lengthens the time course of this pre-motor processing. The time course of this stage is reduced following the removal of the fixation point.

Since superadditivity is a signature of parallel processing in the models currently under consideration, the model predicts that variations in the intensity of auditory and visual components of bimodal signals should produce superadditive interactions on saccade latency. Further, if fixation offsets influence a subsequent stage, the effect of the fixation condition should be additive with all of these sensory effects.

The present experiment tests these predictions by combining the gap paradigm with an expanded version of the factorial paradigm.

\section{Methods}

\subsection{General methods}

A centrally located green light-emitting diode (LED) served as the fixation point. Red LEDs served as the visual targets. The acoustic targets were brief $(100 \mathrm{~ms})$ bursts of white noise delivered through 4-cm speakers located directly beneath the target LEDs. Targets were located to the left and right of fixation at an eccentricity of $20^{\circ}$ (104 cm viewing distance). The entire apparatus was housed in a large $(1.54 \mathrm{~m} \times 1.54 \mathrm{~m} \times 0.9 \mathrm{~m})$ enclosure lined with a sound-absorbing foam material (Sonex). Eye position was digitized at $250 \mathrm{~Hz}$ using an infrared scleral reflection device. Data collection followed $5 \mathrm{~min}$ of dark adaptation, during which time the eye tracker was calibrated. Head movements were minimized using a biteplate. All subjects were emmetropic and had normal hearing. Saccades were identified using a velocity criterion (generally $50 \mathrm{deg} \cdot \mathrm{s}^{-1}$ ). Data analysis was performed off-line.

\subsection{Procedures}

Each observer was given extensive practice on the saccade task. During these practice sessions, the intensities of the auditory and visual targets were varied in order to obtain a reliable intensity effect in each modality for all six observers (recall that the predictions of superadditivity rely on robust ordering of the survivor functions; Appendix 1). Auditory intensities ranged from 39 to $84 \mathrm{~dB}_{\text {spl }}$. Visual intensities ranged from 0.003 to 8.66 $\mathrm{cd} \cdot \mathrm{m}^{-2}$. The subjects then participated in four experimental sessions consisting of 5 blocks of 80 trials (400 trials/session). Auditory, visual, and bimodal targets were presented with equal frequency and randomized with respect to both order and location. In half of the trials, the fixation stimulus was extinguished $200 \mathrm{~ms}$ prior to the onset of the target (gap condition); the fixation stimulus remained illuminated in the other half (overlap condition). Gap and overlap trials were randomly intermixed within each trial block. Acoustic warning signals $(1000 \mathrm{~Hz}, 100 \mathrm{~ms}$ duration) were presented through a center speaker $300 \mathrm{~ms}$ before target onset. Thus, the offset of the warning signal was synchronous with the offset of the fixation point in gap trials. Twenty percent of the trials involved catch trials.

\section{Results}

\subsection{False alarm rates}

The probability of a saccade occurring on catch trials is given in Table 1. False alarm rates were analyzed using a test for the difference between the proportions of false alarms in each condition (Wolpole and Myers 1972 p. 261). This test indicated that the false alarm rates were significantly higher in the gap condition than the overlap condition $(z=-7.148, \alpha<0.001)$. This effect might be interpreted as indicating that a state of disengaged fixation increases the likelihood that a saccade will occur, even in the absence of a target. The magnitude of the gap effect was negatively correlated with the false alarm rate (Spearman rank correlation coefficient, $r_{\text {ranks }}=-0.657$ ), but the strength of the correlation was not significant (critical $r_{\text {ranks }}$ for $n=6$ is \pm 0.8 ). 
Table 1. False alarm rates

\begin{tabular}{llllllll}
\hline Condition & Subj. 1 & Subj. 2 & Subj. 3 & Subj. 4 & Subj. 5 & Subj. 6 & Mean \\
\hline Gap & 0.18 & 0.09 & 0.075 & 0.05 & 0.031 & 0.056 & 0.080 \\
Overlap & 0.04 & 0.13 & 0.00 & 0.00 & 0.013 & 0.013 & 0.013 \\
Mean & 0.11 & 0.11 & 0.038 & 0.025 & 0.022 & 0.035 & 0.047 \\
\hline
\end{tabular}

Table 2. Visual intensity by fixation additivity on mean saccadic reaction time (SRT)

\begin{tabular}{lll}
\hline Fixation condition & Low intensity (ms) & High intensity (ms) \\
\hline Overlap & 264.65 & 190.3 \\
Gap & 228 & 149.35 \\
\hline
\end{tabular}

Mean contrast: -4.3

Table 3. Auditory intensity by fixation (superadditive) interaction on mean SRT

\begin{tabular}{lll}
\hline Fixation condition & Low intensity $(\mathrm{ms})$ & High intensity $(\mathrm{ms})$ \\
\hline Overlap & 253 & 181 \\
Gap & 221 & 163 \\
\hline
\end{tabular}

Mean contrast: 14

Table 4. Bimodal superadditivity: SRTs for overlap condition

\begin{tabular}{lll}
\hline & $\begin{array}{l}\text { Low auditory } \\
\text { intensity (ms) }\end{array}$ & $\begin{array}{l}\text { High auditory } \\
\text { intensity (ms) }\end{array}$ \\
\hline Low visual intensity & 209.7 & 167.25 \\
High visual intensity & 174.45 & 153.8 \\
\hline
\end{tabular}

Mean contrast: 21.8

Table 5. Bimodal superadditivity: SRTs for gap condition

\begin{tabular}{lll}
\hline & $\begin{array}{l}\text { Low auditory } \\
\text { intensity }(\mathrm{ms})\end{array}$ & $\begin{array}{l}\text { High auditory } \\
\text { intensity }(\mathrm{ms})\end{array}$ \\
\hline Low visual intensity & 176.15 & 150.9 \\
High visual intensity & 141.55 & 133.45 \\
\hline
\end{tabular}

Mean contrast: 17.15

\subsection{Analyses of the means}

ANOVAs were performed in the three parts: the unimodal visual target $x$ fixation condition, the unimodal auditory target $\times$ fixation condition, and the bimodal target $\times$ fixation condition. Mean SRTs for each condition are summarized in Tables 2-5.

The visual ANOVA revealed significant effects of both target intensity $\left(F_{(1,5)}=18.18, P<.01\right)$ and fixation condition $\left(F_{(1,5)}=55.87, P<.01\right)$, but the interaction was not significant $\left(F_{(1,5)}=0.19\right.$, NS). This additivity between target luminance and fixation offsets supports the hypothesis that target luminance and fixation point offsets selectively influence serially organized processes.
The auditory ANOVA also revealed significant effects of target intensity $\left(F_{(1,5)}=22.6, P<.01\right)$ and fixation condition $\left(F_{(1,5)}=12.28, P<.01\right)$. These results confirm a previous finding that fixation point offsets facilitate saccades to acoustic as well as visual targets (Fendrich et al. 1991). There is also the suggestion of a weak interaction between auditory target intensity and fixation condition $\left(F_{(1,5)}=7.59, P<.05\right)$.

The results of the bimodal target $\times$ fixation condition ANOVA confirm significant effects of both visual and auditory intensity $\left(F_{(1.5)}=9.9, \quad P<.03\right.$; $F_{(1,5)}=10.17, P<.03$, respectively). Moreover, the interaction between visual and auditory intensity was superadditive $\left(F_{11.5)}=5.85, P<.06\right)$, suggesting that the auditory and visual inputs are indeed processed in parallel. Although the statistical magnitude of this superadditivity is modest, the conclusion of parallel processing is also manifest in the distributional analyses presented in Sect. 3.3.1.

A reliable gap effect was observed for the bimodal targets $\left(F_{(1,5)}=17.11, P<.01\right)$. As the serial stage model predicts, the two-way interaction between fixation offsets and visual intensity was not significant $\left(F_{(1,5)}=0.34\right.$, NS), but the two-way interaction between fixation offsets and auditory intensity was $\left(F_{(1,5)}=6.23, P<.06\right)$. Finally, the triple interaction between auditory intensity, visual intensity and gap condition was not significant $\left(F_{(1,5)}=3.07 ; P>.13\right)$. Although this nonsignificant triple interaction is consistent with a serial stage model of bimodal convergence followed by pre-motor facilitation, the general tendency towards auditory intensity $\times$ fixation interactions is problematic for the simple processing architecture illustrated in Fig. 3. We consider this issue in more detail during our description of the model.

\subsection{Distribution analyses}

3.3.1 Violations of the race inequality. If the CDFs obtained from bimodal targets exceed the sum of the unimodal CDFs, then the redundant targets effect exceeds that predicted by any race model. It is convenient to evaluate race inequality by simply subtracting the CDF obtained from the predicted CDF. Referring to (5), this simply states that, if the results conform to the race model, the following inequality must hold:

$$
\begin{aligned}
\mathbb{R I}(t)= & P\left(\mathrm{RT}_{A \& V} \leqslant t\right) \\
& -\left(P\left(\mathrm{RT}_{A} \leqslant t\right)+P\left(\mathrm{RT}_{V} \leqslant t\right)\right) \leqslant 0
\end{aligned}
$$



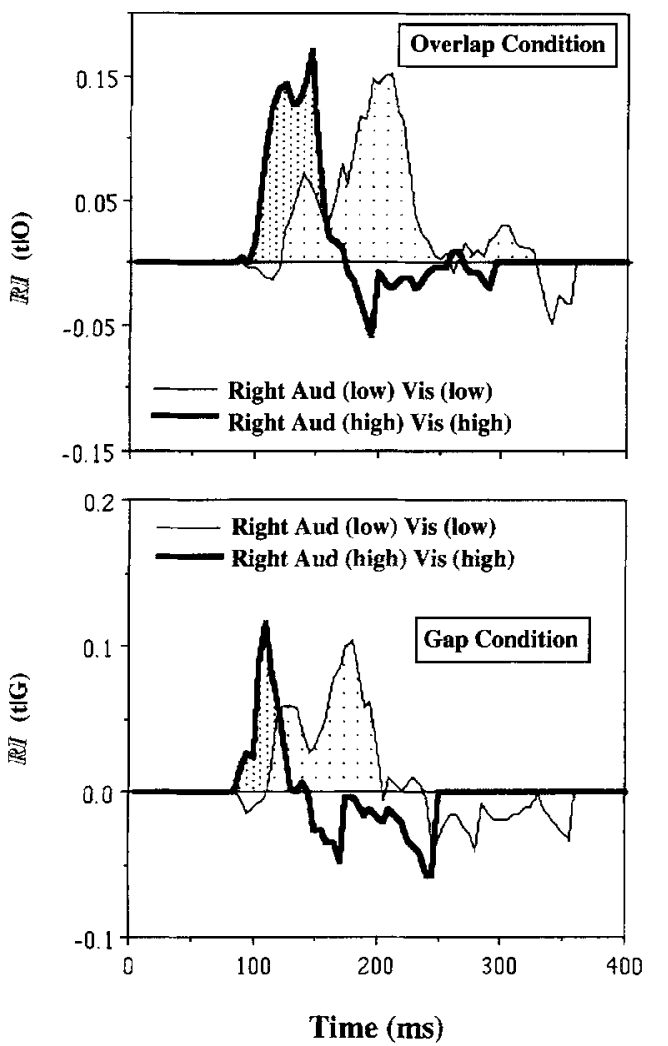

Fig. 4. Average violations of race inequality in both gap and overlap conditions. Positive values indicate violations. See text for details

Stated verbally, the redundant target CDF minus the sum of the unimodal CDFs must be equal to or less than zero for all points in time $t$. We shall refer to this quantity as $\mathbb{R} I(t)$ (race inequality as a function of time). This comparison can be made for each particular instance of redundant targets trial (e.g., $\mathrm{RT}_{A \& V}$ to high intensity targets, presented at the left location in the overlap condition).

There are 96 possible comparisons in the present experiment (16 different redundant target conditions with 6 observers). We therefore present averaged values of (6) in both the gap and overlap conditions. Figure 4 illustrates the low auditory intensity/low visual intensity conditions $\left(A_{\mathrm{L}}, V_{\mathrm{L}}\right)$ and the high auditory intensity/high visual intensity conditions $\left(\mathscr{A}_{\mathrm{H}}, V_{\mathrm{H}}\right)$. Equivalent effects were seen in the other conditions $\left(A_{\mathrm{L}}, V_{\mathrm{H}}\right.$ and $\left.A_{\mathrm{H}}, V_{\mathrm{L}}\right)$. All six observers showed consistent and robust violations in both the gap and overlap conditions; of the 96 possible, there were 89 violations. We conclude that the results provide evidence for neural summation between auditory and visual afferent activities within the human oculomotor system. Further, this conclusion extends to saccades generated in the gap condition. We interpret these violations of race inequality as a behavioral manifestation of the electrophysiological evidence of bimodal convergence within the saccadic control system (e.g., Jay and Sparks 1987, 1990; Meredith and Stein 1983; Peck 1987; Stein and Meredith 1990).

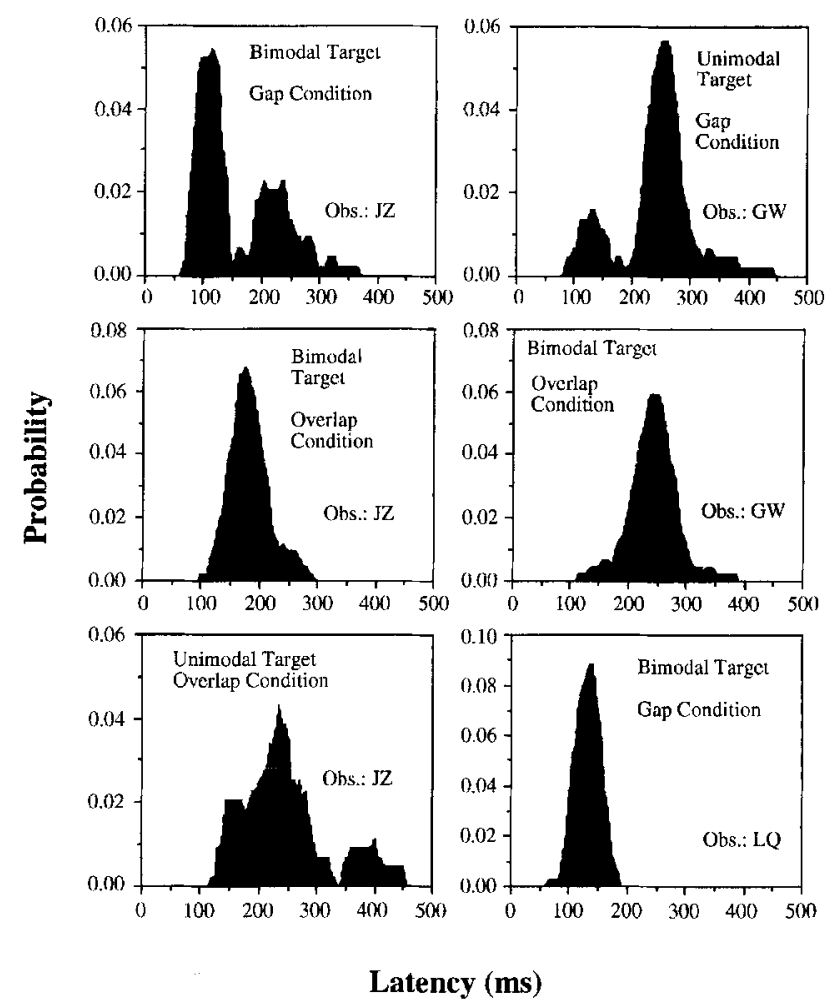

Fig. 5. Selected distributions of saccade latencies under the various experimental conditions

\subsection{Latency distributions in the gap and overlap conditions}

A number of previous investigations have observed that the distribution of saccade latencies obtained in paradigms similar to the present one tend to reveal more than one mode. Fischer and colleagues (e.g., Fischer and Boch 1983) regard the presence of an early mode occurring around $100 \mathrm{~ms}$ as the defining feature of express saccades. Previous work in our laboratory failed to produce reliable evidence of bimodal latency distributions (e.g., Fendrich et al. 1991; Reuter-Lorenz et al. 1991), although isolated cases were observed. The issue of bimodality in these distributions has thus become a point of some controversy (e.g., Wenban-Smith and Findlay 1991; Fischer and Weber 1993; Kingstone and Klein 1993a, b; Reuter-Lorenz and Hughes 1993).

We examined each of the 192 latency distributions produced in this data set $(16$ stimulus conditions $\times 6$ observers $\times 2$ fixation conditions). Twenty-three percent (44/192) clearly had multiple modes. Many others did not have clearly defined modes but could still have come from a mixture of two distributions. For example, in the normal distribution case with equal mixing weights, the mixture distribution will not exhibit multiple modes unless the following criteria are met (Titterington et al. 1985, p. 48):

$\left|E\left(v_{1}\right)-E\left(v_{2}\right)\right| / S D>2$

Examples are illustrated in Fig. 5. They were selected to include some of the clearest examples of multiple modes 
as well as one clear example of a single mode. They also represent a variety of experimental conditions. Most of the clear cases of unimodal distributions came from the gap condition $(32 / 44,73 \%)$. All six subjects produced at least one bimodal latency distribution, although $70 \%$ (31/44) of the total came from two observers (GW and JZ). Thus, we think the status of multimodal latency distributions as a defining characteristic of express saccades remains problematic. However, it also seems clear that SRT distributions can represent mixture distributions. The similarities between these SRT distributions and those reported by Fischer and colleagues seem quite compelling, and we interpret them as replications of their earlier work (e.g., Boch and Fischer 1983; Fischer and Boch 1983; Fischer and Weber 1993). We regard the occurrence of bimodal latency distributions as a probabilistic aspect of performance in these tasks and incorporate this probabilistic feature into the model presented in Sect. 5 .

\section{Discussion}

These results provide robust evidence for neural summation between auditory and visual inputs within the human oculomotor pathways. Given the importance of the superior colliculus (SC) in generating saccades, the convergence of visual and auditory inputs within the SC (e.g., Jay and Sparks 1987, 1990; Peck 1987; Stein and Meredith 1990) provides a likely substrate for the bimodal summation effects observed here.

Additivity between the fixation offsets and sensory factors (Reuter-Lorenz et al. 1991; Kingstone and Klein 1993b; present results) suggests that a separable stage, arranged in series with this sensory stage, is responsible for express saccades (Fig. 3). Evidence that the gap effect is particularly robust for saccades (Iwasaki 1990; Reuter-Lorenz et al. 1991, 1995) is consistent with the suggestion that the gap effect is more closely associated with generating saccades than with the afferent proccessing of the target per se. We therefore refer to the facilitatory effects of fixation point offsets as 'fixation release'. It is noteworthy that the threshold current needed to elicit saccadic eye movements by electrical microstimulation is reduced if the fixation point is removed prior to the delivery of the stimulation (Goldberg et al. 1986), a finding we view as being compatible with the idea of fixation release. The observations of Goldberg et al. (1986) may also relate to an increased incidence of false alarms observed in the gap condition.

The serial stage hypothesis is consistent with the pattern of activity displayed by collicular neurons in gap and overlap conditions. In a study of sensory-motor burst cells in the primate SC, Rohrer and Sparks (1986) report that neither the magnitude of the sensory discharge nor that of the presaccadic discharge is altered by express saccades. It is a reduction in the temporal interval between these discharges that accounts for the facilitation of SRTs in the gap paradigm. We interpret this important finding as support for the idea that fixation release (and the occurrence of express saccades) may be viewed in terms of a facilitated transition from sensory processing to motor commands within the oculomotor system.

\section{A parallel-serial model of bimodal summation and express saccades}

Analysis of SRTs by factorial methods leads to the following conclusions concerning the functional architecture of the human oculomotor system: (1) auditory and visual inputs are conveyed over parallel pathways and summed within the saccadic control system, and (2) the mechanism(s) responsible for express saccades is (are) arranged in series with those responsible for this auditory-visual integration. These points, in addition to the evidence that the distributions of saccade latencies obtained using this paradigm can produce multiple modes in the SRT histograms, are the major empirical conclusions of the present work.

We now develop a model of this processing architecture. The model shares certain similarities with previous models of express saccades (e.g., Reulen 1984 a, b; Fischer and Rogal 1986 a, b; Fischer 1987) and in some ways may be viewed as an elaboration of them. Perhaps the most notable similarity is that each of these models assumes serially organized processing stages. An important implication of the present model is a prediction (developed below) that the joint effects of signal strength and fixation relese should actually vary with gap duration.

\subsection{Description of the model}

We begin with the simple two-stage model illustrated in Fig. 3. The serially organized stages lead to the assertion that the saccadic RT in a given experimental condition is the sum of a sensory processing time, a pre-motor processing time, and a motor execution time. Thus, the mean $\mathrm{RT}$ in the gap condition is given by

$\overline{\mathrm{RT}}_{\mathrm{S}(\mathrm{.}), \mathrm{G}}=\overline{\mathrm{T}}_{\mathrm{S}(\mathrm{f})}+\overline{\mathrm{T}}_{\mathrm{F}(\mathrm{D})}+\overline{\mathrm{T}}_{\mathrm{M}}$.

Similarly, the mean RT in the overlap condition is

$\overline{\mathrm{RT}}_{\mathrm{S}(\cdot), \mathrm{O}}=\overline{\mathrm{T}}_{\mathrm{S}(\cdot)}+\overline{\mathrm{T}}_{\mathrm{F}(\mathrm{E})}+\overline{\mathrm{T}}_{\mathrm{M}}$.

The subscript $S($.$) represents the factor specifying the$ saccade target (either auditory, visual, or bimodal), and the dot within the parentheses represents a particular, but unspecified, intensity level. The additional subscript ( $\mathrm{G}$ or $\mathrm{O}$ ) indicates that the mean comes from either the gap $(\mathrm{G})$ or overlap $(\mathrm{O})$ trials. $T_{\mathrm{S}}$ is a random variable representing the time course of sensory processing. $\overline{\mathrm{T}}_{\mathrm{S}}$ is the expected value of $T_{S}$, is inversely related to stimulus intensity (e.g., Teichner and Krebs 1972), and is also reduced by bimodal stimulation (e.g., Meredith and Stein 1983). Given the results of Hughes et al. (1994) and the present results, we represent the convergence between the visual and auditory channels with a summation operator $(\Sigma)$.

$T_{\mathrm{M}}$ represents the motor time. Following Fischer and Rogal (1986 a, b), we estimate the duration of this stage 
from the latency of saccades elicited by electrical stimulation of the SC (Robinson 1972) and the lead time of presaccadic burst neurons (e.g., Wurtz and Albano 1980). By these criteria, the mean of $T_{M}\left(\bar{T}_{M}\right)$ is approximately $30 \mathrm{~ms}$. We assume that the duration of $T_{\mathrm{M}}$ is independent of both the sensory time $\left(T_{\mathrm{S}(.)}\right)$ and the premotor time $\left(T_{\mathrm{F}}\right)$. Support for this assumption comes from the work of Rohrer and Sparks (1986).

The premotor stage has two states, which are termed states of engaged fixation and disengaged fixation. ${ }^{1}$ The model assumes that the duration of the pre-motor stage is shorter in the disengged state $(F(D))$ than in the engaged state $(F(E))$, and that extinguishing the fixation point produces the disengaged state. Define the average time course of the disengaged state to be $\overline{\mathrm{T}}_{\mathrm{F}(\mathrm{D})}$, and the average time course of the engaged state to be $\bar{T}_{F(E)}$. Since $\overline{\mathrm{T}}_{\mathrm{F}(\mathrm{D})}<\overline{\mathrm{T}}_{\mathrm{F}(\mathrm{E})}, \overline{\mathrm{RT}}_{\mathrm{G}}<\overline{\mathrm{RT}}_{\mathrm{o}}$. Thus, according to the model, $\overline{\mathrm{RT}}$ 's in the gap condition are reduced because removal of the fixation point produces a state of disengaged fixation, which reduces the average duration of the premotor stage from $\overline{\mathrm{T}}_{\mathrm{F}(\mathrm{E})}$ to $\overline{\mathrm{T}}_{\mathrm{F}(\mathrm{D})}$. Given evidence that fixation offsets selectively influence a postsensory stage (Reuter-Lorenz et al. 1991; Rohrer and Sparks 1986; present results), the serial organization of $\overline{\mathrm{T}}_{\mathrm{S}}$ and $\overline{\mathrm{T}}_{\mathrm{F}}$ produces additivity between target parameters (intensity, bimodal summation) and fixation offsets, as is required by the results.

According to the model, express saccades are saccades generated in the disengaged state. It is not possible to assign an arbitrary latency to them because the latency of a saccade also depends on the sensory time $T_{\mathrm{S}}$, which is independent of the fixational state.

\subsection{Demonstration of the model's behavior}

5.2.1 Effects of base time on the magnitude of observed violations of race inequality. This model makes some additional predictions that can be evaluated against the results. For example, the inference that visual and auditory afferent activities are summed within the oculomotor system is based on the overall latency of the saccades. Of course, it is not possible to directly measure the 'detection time' of a stimulus, and RT experiments can only measure the total time elapsed between a stimulus input and motor output. Stages that follow sensory processing can contaminate analyses of $T_{\mathrm{S}}$. We refer to the duration of all processing stages that follow sensory processing as the 'base time' (e.g., $\overline{\mathrm{T}}_{\mathrm{F}(\mathrm{D})}+\overline{\mathrm{T}}_{\mathrm{M}}$, or $\left.\bar{T}_{F(E)}+\bar{T}_{M}\right)$. As the base time increases, the magnitude

\footnotetext{
${ }^{1}$ Fischer and colleagues have suggested that the reduction of saccade latencies in the gap paradigm is mediated by a state of disengaged attention rather disengaged fixation. These two concepts may have features in common, but may also be very different in connotation. We regard the role of attentive mechanisms as far from being established, and so prefer the more neutral term "disengaged fixation". It is important to note however, that the essential feature of the current model, and that suggested by Fischer and Boch (1983), is that the gap effect is mediated by shortening the duration of a processing stage that is arranged in series with both sensory processes and motor execution.
}

of race inequality violations will be reduced (see Appendix 2).

Since the model assumes that the longer RTs in the overlap condition result from the slower time course of premotor processing in the state of engaged fixation, we are in essence assuming a longer base time in the overlap condition relative to the gap condition. This implies that the violations should be smaller in the overlap condition. The data are inconsistent with this prediction (Fig. 4).

The model in Fig. 3 will not produce bimodal latency distributions unless we assume that the engaged and disengaged states are probabilistically controlled by fixation point offsets. We feel that the present results, in conjunction with the earlier findings of Fischer and colleagues (e.g., Fischer and Boch 1983; Fischer and Weber 1993), compel us to adopt the view that models of the saccadic control system should be able to account for observations of bimodal latency distributions. A model proposed by Fischer and Rogal (1986 a, b) was specifically designed to produce multiple modes in SRT distributions using (implied) probabilistic control processes. The basic components of the Fischer-Rogal model are (1) $\mathbb{A}$ : an afferent processing stage, (2) $\mathbb{F}$ : a process which is responsible for releasing the eyes from current attentive fixation before the next saccade occurs, (3) $\mathbb{D}$ : a decision process, (4) $\mathbb{C}$ : a computation process, and $(5) \mathbb{E}$ : the efferent processing stage. The Fischer-Rogal model is also a serial process model. Thus, SRTs in the gap condition can be expressed as follows:

Express: $\mathrm{SRT}=\mathbb{A}+\mathbb{C}+\mathbb{E}$

and

Regular: $\mathrm{SRT}=\mathbb{A}+\mathbb{D}+\mathbb{C}+\mathbb{E}$

For the overlap condition, the SRT is given by:

Express: $\mathrm{SRT}=\mathbb{A}+\mathbb{C}+\mathbb{E}$

and

Regular: $\mathrm{SRT}=\mathbb{A}+\mathbb{F}+\mathbb{D}+\mathbb{C}+\mathbb{E}$

Since there are two states of both the gap and overlap conditions, the predicted histograms can reveal at least two modes. The mixture probabilities for the two states were left unspecified in the description of Fischer and Rogal (1986a, b), however. These mixture probabilities must be specified in order to generate actual predictions. Let $p_{G e x}$ be the probability that the observer is in the express (disengaged) state in the gap condition, $p_{\text {Greg }}$ be the probability that the observer is in the regular (engaged) state in the gap condition. The corresponding probabilities in the overlap condition are $p_{\text {Oex }}$ and $p_{\text {Oreg }}$. If $p_{\text {Gex }}=p_{\text {Oex }}$ and $p_{\text {Greg }}=p_{\text {Oreg }}$, then the Fischer-Rogal model is able to predict additivity between sensory factors and the gap effect. Notice however that, as with the present model, the Fischer-Rogal model assumes that the base time is longer in the overlap than in the gap condition. Thus, it also incorrectly predicts that the magnitude of the race inequality violations is greater in the gap than the overlap conditions. In addition, notice that, given the 
probabilities needed to produce additivity between sensory factors and fixation release, the Fischer and Rogal (1986) model predicts an equal frequency of 'express saccades' in the gap and overlap conditions. That is, if $p_{\mathrm{Gex}}=p_{\text {Oex }}$ and $p_{\mathrm{Greg}}=p_{\text {Oreg }}$, the only difference between SRT distributions from gap and overlap trials is the addition of the ' $F$ ' stage. However, fixation point offsets are thought to increase the incidence of express saccades.

It is therefore necessary to modify this general class of serial stage model to account for (1) mixture distributions and (2) the proper ordering of race inequality violations in the gap and overlap conditions.

5.2.2 Producing bimodal latency distributions: probabilistic mixtures of the engaged and the disengaged states. Mixture distributions suggest that the states of engaged and disengaged fixation are generated probabilistically in both the gap and overlap trials. Thus, we wish to create a model in which the probability of being in the engaged state during overlap trials is not necessarily 1.0 (although it can be, and if the latency distributions are truly unimodal, then it must be). We define the probability of being in the engaged state, given a low target intensity $(S(1))$ on an overlap trial $(\mathrm{O})$ as $P(\mathrm{E} \mid \mathrm{S}(1) \& \mathrm{O})$. The probability of being in the disengaged state on overlap trials is thus $P(\mathrm{D} \mid \mathrm{S}(1) \& \mathrm{O})=1-P(\mathrm{E} \mid \mathrm{S}(1) \& \mathrm{O})$. Similarly, we define the probability of being in the engaged state, given a low target intensity $(\mathrm{S}(1))$ on a gap trial $(\mathrm{G})$ as $P(\mathrm{E} \mid \mathrm{S}(1) \& \mathrm{G})$, and the probability of being in the disengaged state is therefore $P(\mathrm{D} \mid \mathrm{S}(1) \& \mathrm{G})=1-P(\mathrm{E} \mid \mathrm{S}(1) \& \mathrm{G})$. The mean RT for a given fixation condition is then the sum of the average time course of each component process, and the average time course of the premotor process is given by the sum of the engaged and the disengaged states, weighted by the appropriate probabilities.

Juttner and Wolf (1994) have taken a similar approach in a model designed to account for the sequential effects of catch trials on express saccades. Their model uses a Markov chain to determine the transition probabilities between the engaged and disengaged states, which they term the E state (express saccade preparation state) and the R state (regular saccade preparation state). Although Juttner and Wolf found that the conditions of the present experiment did not produce robust sequential effects, similar Markov processes could readily be incorporated into the present model if needed.

\subsubsection{Producing the correct ordering of race inequality} violations: decomposition of the premotor time into a random and a deterministic component. The model must also be modified to account for the finding that the magnitude of race inequality violations is greater in the overlap than in the gap condition. Referring back to (6), let us denote this ordering as $\mathbb{R} \mathbb{I}(t \mid O)-\mathbb{R} \mathbb{I}(t \mid G)>0$, where $\mathbb{R} \mathbb{I}(t \mid O)$ is the magnitude of the race inequality violation at time $t$ in the overlap condition, and $\mathbb{R} I(t \mid \mathrm{G})$ is the corresponding quantity in the gap condition. As indicated in Appendix 2, if lengthening of the saccadic latencies in the overlap condition is attributed to an increase in the premotor component of the base time, and the base time is a random variable, then the expected result is $\mathbb{R} I(t \mid \mathrm{O})-\mathbb{R} I(t \mid \mathrm{G})<0$. In contrast, if the duration of the premotor stage is deterministic, then $\mathbb{R} \mathbb{I}(t \mid \mathrm{O})-\mathbb{R} \mathbb{I}(t \mid \mathrm{G})=0$, even if the delays associated with the engaged state are longer than those of the disengaged state.

However, if the premotor processing time is a mixed variable with a deterministic as well as a random component, then the overall duration of the engaged state can be longer than the disengaged state, and the condition that $\mathbb{R} \mathbb{I}(t \mid \mathrm{O})-\mathbb{R} \mathbb{I}(t \mid \mathrm{G})>0$ can still be met. This condition requires (1) a longer deterministic component in the engaged than the disengaged state, (2) the CDF of the random component to be greater in the gap than the overlap condition for all times $t$, and (3) ordering the sum of the two components so that the CDF of the disengaged state is larger (i.e., faster processing time) than the $\mathrm{CDF}$ for the engaged state.

The idea that there is both a random and a deterministic component for fixation durations was proposed by Harris et al. (1988), who showed that a delayed exponential distribution fits the distribution of fixation durations obtained from both children and adults. The delay can be considered as a deterministic dead time, which is added to a random delay that is exponentially distributed. Harris et al. (1988) observed that the fixation durations of children were shorter than those of adults and that, at the minimum, fixation durations were similar to express saccade latencies. Since the processes that occur during fixation must surely include those associated with the generation of the next saccade, we regard the current suggestion that saccadic premotor processing includes a deterministic and a random component as similar to the formulation of Harris et al. (1988).

We assign the following premotor time variables to the above defined states, $\mathrm{E}$ and $\mathrm{D}$ :

Case (1) in the E state, the premotor time is selected to be $T_{E 1}+T_{E 2}$, where $T_{E 1}$ is a deterministic dead time and $T_{\mathrm{E} 2}$ is a random variable.

Case (2) in the $\mathrm{D}$ state, the premotor time is selected to be $T_{\mathrm{D} 1}+T_{\mathrm{D} 2}$, where $T_{\mathrm{D} 1}$ is a deterministic dead time and $T_{\mathrm{D} 2}$ is a random variable.

We define $\overline{\mathrm{T}}_{\mathrm{F}(\mathrm{E})}=T_{\mathrm{E} 1}+\overline{\mathrm{T}}_{\mathrm{E} 2}$ and $\overline{\mathrm{T}}_{\mathrm{F}(\mathrm{D})}=T_{\mathrm{D} 1}+\overline{\mathrm{T}}_{\mathrm{D} 2}$, and require that $\overline{\mathrm{T}}_{\mathrm{F}(\mathrm{E})}>\overline{\mathrm{T}}_{\mathrm{F}(\mathrm{D})}$.

As before, the mean reaction times for the various conditions are the sum of the sensory time, the motor time, and a mixture of the average time course of premotor processing in the engaged and the disengaged states. Thus, mean RTs for the overlap condition and the gap condition for low-intensity targets are written as

$$
\begin{aligned}
\overline{\mathrm{RT}}_{\mathrm{S}(1), \mathrm{O}}= & \overline{\mathrm{T}}_{\mathrm{S}(1)}+P(\mathrm{E} \mid \mathrm{S}(1) \& \mathrm{O}) \times \overline{\mathrm{T}}_{\mathrm{F}(\mathrm{E})} \\
& +P(\mathrm{D} \mid \mathrm{S}(1) \& \mathrm{O}) \times \overline{\mathrm{T}}_{\mathrm{F}(\mathrm{D})}+\overline{\mathrm{T}}_{\mathrm{M}} \\
= & \overline{\mathrm{T}}_{\mathrm{S}(1)}+P(\mathrm{E} \mid \mathrm{S}(1) \& \mathrm{O}) \times\left(T_{\mathrm{E} 1}+\overline{\mathrm{T}}_{\mathrm{E} 2}\right) \\
& +P(\mathrm{D} \mid \mathrm{S}(1) \& \mathrm{O}) \times\left(\mathrm{T}_{\mathrm{D} 1}+\overline{\mathrm{T}}_{\mathrm{D} 2}\right)+\overline{\mathrm{T}}_{\mathrm{M}}
\end{aligned}
$$


and

$$
\begin{aligned}
\overline{\mathrm{RT}}_{\mathrm{S}(1), \mathrm{G}}= & \overline{\mathrm{T}}_{\mathrm{S}(1)}+P(\mathrm{E} \mid \mathrm{S}(1) \& \mathrm{G}) \times \overline{\mathrm{T}}_{\mathrm{F}(\mathrm{E})} \\
& +P(\mathrm{D} \mid \mathrm{S}(1) \& \mathrm{G}) \times \overline{\mathrm{T}}_{\mathrm{F}(\mathrm{D})}+\overline{\mathrm{T}}_{\mathrm{M}} \\
= & \overline{\mathrm{T}}_{\mathrm{S}(1)}+P(\mathrm{E} \mid \mathrm{S}(1) \& \mathrm{G}) \times\left(T_{\mathrm{E} 1}+\overline{\mathrm{T}}_{\mathrm{E} 2}\right) \\
& +P(\mathrm{D} \mid \mathrm{S}(1) \& \mathrm{G}) \times\left(T_{\mathrm{D} 1}+\overline{\mathrm{T}}_{\mathrm{D} 2}\right)+\overline{\mathrm{T}}_{\mathrm{M}}
\end{aligned}
$$

The corresponding means for the high-intensity targets are

$$
\begin{aligned}
\overline{\mathrm{RT}}_{\mathrm{S}(\mathrm{h}), \mathrm{O}}= & \overline{\mathrm{T}}_{\mathrm{S}(\mathrm{h})}+P(\mathrm{E} \mid \mathrm{S}(\mathrm{h}) \& \mathrm{O}) \times \overline{\mathrm{T}}_{\mathrm{F}(\mathrm{E})} \\
& +P(\mathrm{D} \mid \mathrm{S}(\mathrm{h}) \& \mathrm{O}) \times \overline{\mathrm{T}}_{\mathrm{F}(\mathrm{D})}+\overline{\mathrm{T}}_{\mathrm{M}} \\
= & \overline{\mathrm{T}}_{\mathrm{S}(\mathrm{h})}+P(\mathrm{E} \mid \mathrm{S}(\mathrm{h}) \& \mathrm{O}) \times\left(T_{\mathrm{E} 1}+\overline{\mathrm{T}}_{\mathrm{E} 2}\right) \\
& +P(\mathrm{D} \mid \mathrm{S}(\mathrm{h}) \& \mathrm{O}) \times\left(T_{\mathrm{D} 1}+\overline{\mathrm{T}}_{\mathrm{D} 2}\right)+\overline{\mathrm{T}}_{\mathrm{M}}
\end{aligned}
$$

and

$$
\begin{aligned}
\overline{\mathrm{RT}}_{\mathrm{S}(\mathrm{h}), \mathrm{G}}= & \overline{\mathrm{T}}_{\mathrm{S}(\mathrm{h})}+\mathrm{P}(\mathrm{E} \mid \mathrm{S}(\mathrm{h}) \& \mathrm{G}) \times \overline{\mathrm{T}}_{\mathrm{F}(\mathrm{E})} \\
& +\mathrm{P}(\mathrm{D} \mid \mathrm{S}(\mathrm{h}) \& \mathrm{G}) \times \overline{\mathrm{T}}_{\mathrm{F}(\mathrm{D})}+\overline{\mathrm{T}}_{\mathrm{M}} \\
= & \overline{\mathrm{T}}_{\mathrm{S}(\mathrm{h})}+P(\mathrm{E} \mid \mathrm{S}(\mathrm{h}) \& \mathrm{G}) \times\left(T_{\mathrm{E} 1}+\overline{\mathrm{T}}_{\mathrm{E} 2}\right) \\
& +P(\mathrm{D} \mid \mathrm{S}(\mathrm{h}) \& \mathrm{G}) \times\left(T_{\mathrm{D} 1}+T_{\mathrm{D} 2}\right)+\overline{\mathrm{T}}_{\mathrm{M}}
\end{aligned}
$$

If we assume that $P(\mathrm{D} \mid \mathrm{S}(). \& \mathrm{G})>P(\mathrm{D} \mid \mathrm{S}(). \& \mathrm{O})$, then we have $\overline{\mathrm{RT}}_{\mathrm{S}(.), \mathrm{o}}>\overline{\mathrm{RT}}_{\mathrm{S}(.), \mathrm{G}}$. That is, if the probability of being in the disengaged state is greater in the gap than in the overlap condition, then the mean RT in the gap condition will be less than in the overlap condition.

In order to reconcile the observation that $\mathbb{R} I(t \mid \mathrm{O})-\mathbb{R} I(t \mid \mathrm{G})>0$ with the assumption that the premotor component of the base time is longer in the overlap than in the gap condition, we decompose the total premotor time into a deterministic and a random component. To predict $\mathbb{R} I(t \mid \mathrm{O})-\mathbb{R} \mathbb{I}(t \mid \mathrm{G})>0$, we need a cumulative distribution ordering of the random times, $T_{\mathrm{E} 2}$ and $T_{\mathrm{D} 2}$, that is $F_{\mathrm{E} 2}(t)>F_{\mathrm{D} 2}(t)$. However, this alone will predict an opposite effect on the gap condition: the speed of processing becomes slower in the gap condition. If we assume $F_{\mathrm{E} 2}(t)>F_{\mathrm{D} 2}(t)$, but with the deterministic delays, $F_{\mathrm{E} 2}\left(t-T_{\mathrm{E} 1}\right)<F_{\mathrm{D} 2}\left(t-T_{\mathrm{D} 1}\right)$, we can predict the proper ordering of both the magnitudes of race inequality violations and the average latencies of saccades in the gap and overlap conditions. That is to say, the mean of the random component of the premotor time is larger in the gap trials, but the deterministic component in the overlap trials is sufficiently long such that the total duration of premotor processing is longer in the overlap trials. Such a situation might arise, for example, if premotor processes in the engaged state involve a number of long-length pathways (producing a long deterministic delay) whereas processing in the disengaged state involves multisynaptic local circuit pathways (producing shorter deterministic delays, but a larger variable component).
5.2.4 A numerical implementation of the model's behavior. We now describe a numerical implementation which shows that the model (1) generates multimodal latency distributions, (2) implements neural summation between visual and auditory afferents and correctly captures the magnitude of the race inequality violations in the gap and overlap conditions, and (3) produces additivity between fixation release and visual target intensity (mean contrast $=0$ ). For the purposes of simplicity and clarity, the motor time is left out of the simulation (so long as $\overline{\mathrm{T}}_{\mathrm{M}}$ is not influenced by the duration of the remaining component processes, $\overline{\mathrm{T}}_{\mathrm{M}}$ makes no contribution to the pattern of results). The implementation of the model is as follows:

For the gap condition,

$$
\begin{array}{r}
\mathrm{RT}_{\mathrm{S}(.), \mathrm{G}}=T_{\mathrm{S}(.)}+q 1\left(T_{\mathrm{D} 1}+T_{\mathrm{D} 2}\right)+q 2\left(T_{\mathrm{E} 1}+T_{\mathrm{E} 2}\right), \\
\text { where } q 1+q 2=1
\end{array}
$$

For the overlap condition,

$$
\begin{array}{r}
\mathrm{RT}_{\mathrm{S}(1), \mathrm{O}}=T_{\mathrm{S}(.)}+p 1\left(T_{\mathrm{D} 1}+T_{\mathrm{D} 2}\right)+p 2\left(T_{\mathrm{E} 1}+T_{\mathrm{E} 2}\right), \\
\text { where } p 1+p 2=1
\end{array}
$$

Thus, two basis components are mixed probabilistically in both the gap condition and the overlap condition. We use the two-stage Erlang ${ }^{2}$ distribution to model the sensory time $\left(T_{\mathrm{S}(.)}\right)$ and the exponential distribution to model the various $T_{\mathrm{D} 2}$ and $T_{\mathrm{E} 2}$ distributions. The deterministic delays are $T_{\mathrm{D} 1}$ and $T_{\mathrm{E} 1}$.

The simulation was performed using Mathematica, and some results are illustrated in Figs. 6 and 7. The model produces bimodal latency distributions in any desired mixture (examples in Fig. 6) and fulfills the requirement that $\mathbb{R} I(t \mid \mathrm{O})-\mathbb{R} \Pi(t \mid \mathrm{G})>0$ (Fig. 7).

5.2.5 Implementing probabilistic selection between states of engaged and disengaged fixation. It is useful to consider potential mechanism(s) that would generate mixtures between the engaged and disengaged fixation states.

\footnotetext{
${ }^{2}$ Survivor function of the two-stage Erlang distribution is written $\overline{\mathrm{F}}_{T_{\mathrm{s}}}(t)=\sum_{k=0}^{1} \frac{\left(\left(\lambda_{\mathrm{A}}+\lambda_{\mathrm{V}}\right) t\right)^{k}}{k !} \exp \left[-\left(\lambda_{\mathrm{A}}+\lambda_{\mathrm{V}}\right) t\right]$,
}

where $\lambda_{\mathrm{A}}$ is the rate of the auditory channels-activity and $\lambda_{\mathrm{y}}$ is the rate of the visual channels' activity. The activity level of both auditory and visual channels are modeled by a Poisson process. Since the sensory processing time is summed with an exponential premotor time and a deterministic delay $\tau$, we have a convolution of the two-stage Erlang density function with the exponential density function. The exponential density function is written as

$f_{T p: s}(t)=\alpha \exp [-\alpha(t-\tau)]$

The survivor function of the convolution of these two density functions is written as

$$
\begin{aligned}
\overline{\mathrm{F}}_{T_{\mathrm{s}}+T_{\mathrm{rM}}(t)=} & \frac{\alpha}{\lambda-\alpha}\left\{\frac{\lambda^{2}-\alpha \lambda+\alpha}{\alpha(\lambda-\alpha)} \exp (-\alpha[t-\tau])\right. \\
& -(\lambda-\alpha+1+[t-\tau]) \exp (-\lambda[t-\tau])\}
\end{aligned}
$$

where $\lambda=\lambda_{\mathrm{A}}+\lambda_{\mathrm{V}}$ 


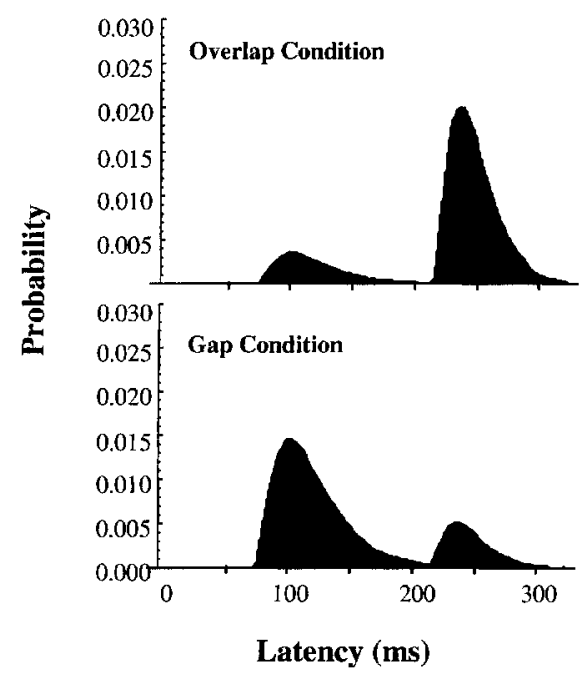

Fig. 6. Simulated latency distributions using the model described in the text. Latency and variance of each mode are determined by model parameters and are therefore arbitrary and easily modified

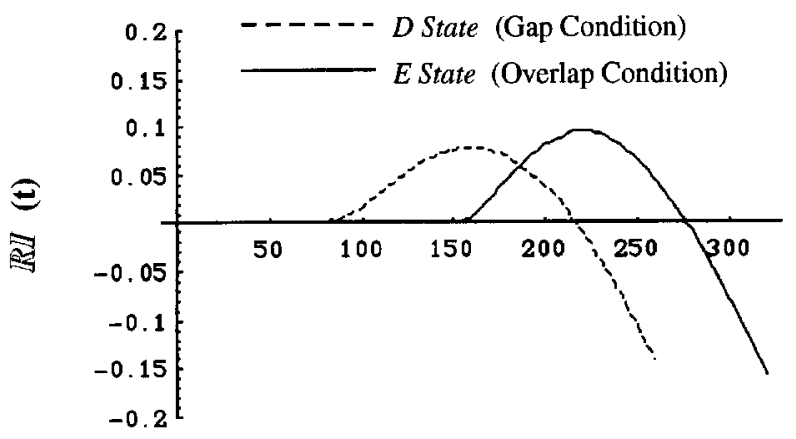

Time (ms)

Fig. 7. Simulations of neural summation and resulting magnitudes of race model inequality $[\mathbb{R} \Pi(t)]$ using the model described in the text

One possible implementation runs as follows. During active fixation, we suppose that fixation-disengagement neurons discharge at a relatively low frequency. Upon removal of the fixation point, there is a transient increase in this rate of discharge (the sign of these changes are arbitrary). We assume that this fixation-related activity acts as the input to a neural system that operates like a set-reset flip-flop (Fig. 8). If afferent activity associated with the presentation of the saccade target serves as the clock pulse, then the output is high only when pulses from the fixation signal and the sensory signal are coincident. In this way, the flip-flop's output is determined by the frequency (or perhaps the duty cycle) of the fixation signal activity. The engaged and disengaged states are determined by the flip-flop (high output produces disengaged fixation, low output produces engaged fixation). Thus, the probability that the system is in the disengaged state (i.e., proportion of time occupied by the black rectangles in Fig. 8) is determined by the frequency of pulses occurring on the fixation release signal.
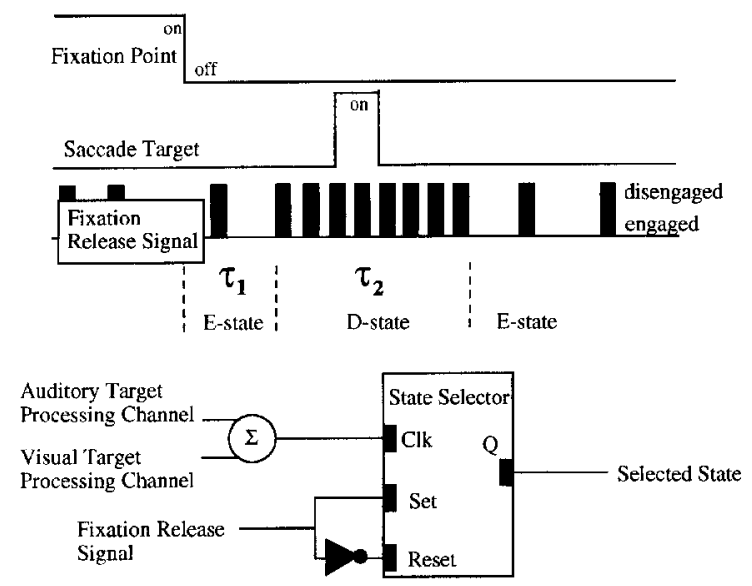

Fig. 8. Hypothetical system for implementing probabilistic switching between the states of engaged and disengaged fixation

For convenience, we define the D state as a transient increase in the probability of being in the disengaged state following the offset of the fixation point. The $E$ state refers to periods of time in which the probability of being in the engaged state is high (Fig. 8).

Another way to implement probability mixtures is to utilize interactive renewal models (e.g., Bishop et al. 1964; Ten Hoopen and Reuver 1965; Coleman and Gastwirth 1969; Pooi and Lee 1975) that were constructed to explain multimodal distributions of interspike intervals in lateral geniculate neurons. These models assume dynamic interactions between an excitatory process and an inhibitory process. In the current context, the excitatory process (initiated by fixation point offsets) could lead to the disengaged state, while the inhibitory process (active fixation) maintains premotor processes in the engaged state. Excitatory events are accumulated over time, and a response (fixation disengagement) occurs if the accumulated number of excitatory events exceeds a threshold value. However, an inhibitory event resets the accumulator (engaged fixation). In addition, there is a delay following the arrival of an inhibitory event. The delay could be deterministic or stochastic.

This interactive renewal model can be viewed as a specific elaboration of the mixture model described above. That is, the interactive renewal process is able to specify the actual proportions of each state underlying the mixture distributions by way of a race between the excitatory and inhibitory processes. If these are Poisson processes with the rates $\lambda_{\mathrm{E}}$ and $\lambda_{\mathrm{I}}$, respectively, the probability that the accumulated excitatory process exceeds the threshold $\theta$ without being reset is $\left(\frac{\lambda_{\mathrm{E}}}{\lambda_{\mathrm{E}}+\lambda_{\mathrm{I}}}\right)^{\theta}$. Let us call this event a 'success'. The average interval between 'successes' is $\frac{\theta}{\lambda_{\mathrm{E}}}$. Given appropriate parameter values, the interval between 'successes' can produce modes in a latency distribution. Therefore, the model can make numerical and in some cases analytical formulations that in future work may contribute to more detailed models of latency distributions. 


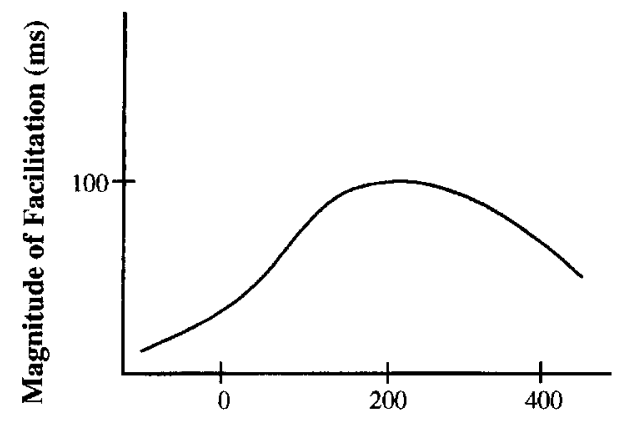

Gap Duration (ms)

Fig. 9. Magnitude of facilitation in the gap paradigm as a function of gap duration [adapted from Saslow (1967) and Iwasaki (1990)]

5.2.6 Temporal dynamics of fixation release. The gap effect first develops and then diminishes over time (Saslow 1967; Fischer and Ramsperger 1984; Mayfrank et al. 1986; Iwasaki 1990; see Fig. 9). Consideration of the relative latency of target detection and fixation release can account for the growth of gap facilitation. Both fixation offsets and peripheral targets are presumably processed in parallel, so we assume these processes race one another at very short gap durations. If the target is detected before the arrival of the fixation release signal, then the system has a high probability of being in the engaged state. If, however, the fixation release signal arrives at the premotor stage before the afferent signal that initiates the saccade, then the likelihood that the saccade occurs in the disengaged state is increased.

We assume the decreases in facilitation at long gap durations result from purely endogenous processes as they presumably depend solely upon the passage of time. In the present context, one might assume that the oculomotor system can only remain in the D state for a limited period of time. We might suppose that the discharge frequency of the fixation signal begins to wane as the gap duration increasingly exceeds the optimal interval (transient response). This would serve to increase the probability that the system is in the engaged state at the moment when the target is detected. Thus, the probability of being in the disengaged state is low for very short gap durations (system still in the E state), increases until the optimal duration is reached (system switches to the D state), and then decreases again because of the limited duration for the $\mathrm{D}$ state.

Figure 10 illustrates these concepts. We define $\tau_{1}$ as the latency of the onset of the D state relative to the offset of the fixation point. We define $\tau_{2}$ as the duration of the $\mathrm{D}$ state. Thus, upon extinguishing the fixation point, the system remains in the $\mathrm{E}$ state for $\tau_{1} \mathrm{~ms}$, then switches to the D state for $\tau_{2}$ ms. $\tau_{1}+\tau_{2}$ ms following the offset of the fixation point, the system settles back into the E state. Selection between the E and D states is determined by the temporal order between the sensory time $\left(T_{\mathrm{s}}\right)$ and the timing of fixation release $\left(\tau_{1}\right)$. If the target's detection time is greater than $\tau_{1}$, but less than $\tau_{1}+\tau_{2}$, then the system is in the D state. In the D state, the probability of disengaged fixation is $p_{\mathrm{D}}$, and the probability of being in

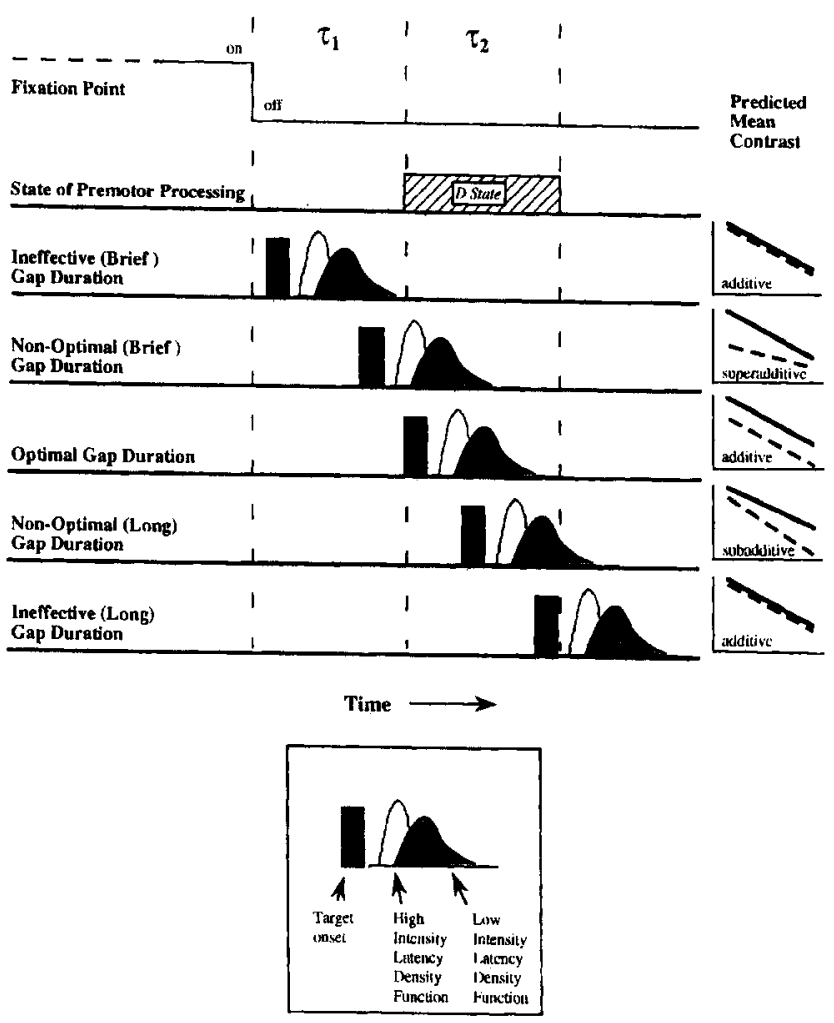

Fig. 10. Illustration of predicted relationship between the relative timing of target detection densities and the onset of the state of disengaged fixation for different gap durations. Panels at right show qualitative predictions of the mean contrasts from a factorial experiment

a state of engaged fixation is $p_{\mathrm{E}}=1-p_{\mathrm{D}}$. Similarly, when the system is in the $\mathrm{E}$ state, the probability of disengaged fixation is $q_{\mathrm{D}}$, and the probability that fixation is in the engaged state is $q_{\mathrm{D}}=1-q_{\mathrm{E}}$. If the target is detected before $\tau_{1}$ (as is likely when the gap duration is brief) or after $\tau_{1}+\tau_{2}$ (likely if the gap duration is long), then the system is in the E state. We assume that $q_{\mathrm{E}}>p_{\mathrm{E}}$, and that $T_{\mathrm{F}(\mathrm{E})}>T_{\mathrm{F}(\mathrm{D})}$, so that the relative timing of fixation release and target detection are important determinants of the average RT. In the overlap condition, the system is in the E state.

\subsection{The mean contrast for the model}

The mean contrast for the gap-by-sensory interaction involves two levels of target intensity (the sensory factor), and two levels of the fixation factor (gap versus overlap). The expression for the mean RT for the low-intensity signals in the overlap condition can be written as follows:

$$
\begin{aligned}
\overline{\mathrm{RT}}_{\mathrm{S}(1), \mathrm{O}}= & \overline{\mathrm{T}}_{\mathrm{S}(1)}+P(\mathrm{E} \mid \mathrm{S}(1) \& \mathrm{O}) \times\left(T_{\mathrm{E} 1}+\overline{\mathrm{T}}_{\mathrm{E} 2}\right) \\
& +P(\mathrm{D} \mid \mathrm{S}(1) \& \mathrm{O}) \times\left(T_{\mathrm{D} 1}+\overline{\mathrm{T}}_{\mathrm{D} 2}\right)+\overline{\mathrm{T}}_{\mathrm{M}}
\end{aligned}
$$

Similarly, the mean RT for low-intensity signals in the gap condition is:

$$
\begin{aligned}
\overline{\mathrm{RT}}_{\mathrm{S}(1), \mathrm{G}}= & \overline{\mathrm{T}}_{\mathrm{S}(1)}+P(\mathrm{E} \mid \mathrm{S}(1) \& \mathrm{G}) \times\left(T_{\mathrm{E} 1}+\overline{\mathrm{T}}_{\mathrm{E} 2}\right) \\
& +P(\mathrm{D} \mid \mathrm{S}(1) \& \mathrm{G}) \times\left(T_{\mathrm{D} 1}+\overline{\mathrm{T}}_{\mathrm{D} 2}\right)+\overline{\mathrm{T}}_{\mathrm{M}}
\end{aligned}
$$


The corresponding means for high intensity signals are written as:

$$
\begin{aligned}
\overline{\mathrm{RT}}_{\mathrm{S}(\mathrm{h}), \mathrm{O}}= & \overline{\mathrm{T}}_{\mathrm{S}(\mathrm{h})}+P(\mathrm{E} \mid \mathrm{S}(\mathrm{h}) \& \mathrm{O}) \times\left(T_{\mathrm{E} 1}+\overline{\mathrm{T}}_{\mathrm{E} 2}\right) \\
& +P(\mathrm{D} \mid \mathrm{S}(\mathrm{h}) \& \mathrm{O}) \times\left(T_{\mathrm{D} 1}+\overline{\mathrm{T}}_{\mathrm{D} 2}\right)+\overline{\mathrm{T}}_{\mathrm{M}}
\end{aligned}
$$

and:

$$
\begin{aligned}
\overline{\mathrm{RT}}_{\mathrm{S}(\mathrm{h}), \mathrm{G}}= & \overline{\mathrm{T}}_{\mathrm{S}(\mathrm{h})}+P(\mathrm{E} \mid \mathrm{S}(\mathrm{h}) \& \mathrm{G}) \times\left(T_{\mathrm{E} 1}+\overline{\mathrm{T}}_{\mathrm{E} 2}\right) \\
& +P(\mathrm{D} \mid \mathrm{S}(\mathrm{h}) \& \mathrm{G}) \times\left(T_{\mathrm{D} 1}+\overline{\mathrm{T}}_{\mathrm{D} 2}\right)+\overline{\mathrm{T}}_{\mathrm{M}}
\end{aligned}
$$

The gap-by-sensory interaction mean contrast is expressed as follows:

$\Delta_{\mathrm{S}, \mathrm{F}}^{2} \overline{\mathrm{RT}}_{\mathrm{S}, \mathrm{F}}=\overline{\mathrm{RT}}_{\mathrm{S}(1), \mathrm{o}}-\overline{\mathrm{RT}}_{\mathrm{S}(1), \mathrm{G}}-\overline{\mathrm{RT}}_{\mathrm{S}(\mathrm{h}), \mathrm{o}}+\overline{\mathrm{RT}}_{\mathrm{S}(\mathrm{h}), \mathrm{G}}$, which by substitution yields

$$
\begin{aligned}
= & P(\mathrm{E} \mid \mathrm{S}(1) \& \mathrm{O}) \times\left(T_{\mathrm{E} 1}+\overline{\mathrm{T}}_{\mathrm{E} 2}\right) \\
& +P(\mathrm{D} \mid \mathrm{S}(1) \& \mathrm{O}) \times\left(T_{\mathrm{D} 1}+\overline{\mathrm{T}}_{\mathrm{D} 2}\right) \\
& -P(\mathrm{E} \mid \mathrm{S}(1) \& \mathrm{G}) \times\left(T_{\mathrm{E} 1}+\overline{\mathrm{T}}_{\mathrm{E} 2}\right) \\
& -P(\mathrm{D} \mid \mathrm{S}(1) \& \mathrm{G}) \times\left(T_{\mathrm{D} 1}+\overline{\mathrm{T}}_{\mathrm{D} 2}\right) \\
& -P(\mathrm{E} \mid \mathrm{S}(\mathrm{h}) \& \mathrm{O}) \times\left(T_{\mathrm{E} 1}+\overline{\mathrm{T}}_{\mathrm{E} 2}\right) \\
& -P(\mathrm{D} \mid \mathrm{S}(\mathrm{h}) \& \mathrm{O}) \times\left(T_{\mathrm{D} 1}+\overline{\mathrm{T}}_{\mathrm{D} 2}\right) \\
& +P(\mathrm{E} \mid \mathrm{S}(\mathrm{h}) \& \mathrm{G}) \times\left(T_{\mathrm{E} 1}+\overline{\mathrm{T}}_{\mathrm{E} 2}\right) \\
& +P(\mathrm{D} \mid \mathrm{S}(\mathrm{h}) \& \mathrm{G}) \times\left(T_{\mathrm{D} 1}+\overline{\mathrm{T}}_{\mathrm{D} 2}\right)
\end{aligned}
$$

The mean contrast is 0 if $P(\mathrm{E} \mid \mathrm{S}(1) \& \mathrm{O})=P(\mathrm{E} \mid \mathrm{S}(\mathrm{h}) \& \mathrm{O})$, $P(\mathrm{D} \mid \mathrm{S}(1) \& \mathrm{O})=P(\mathrm{D} \mid \mathrm{S}(\mathrm{h}) \& \mathrm{O}), \quad P(\mathrm{D} \mid \mathrm{S}(1) \& \mathrm{G})=$ $P(\mathrm{D} \mid \mathrm{S}(\mathrm{h}) \& \mathrm{G})$, and $P(\mathrm{E} \mid \mathrm{S}(1) \& \mathrm{G})=P(\mathrm{E} \mid \mathrm{S}(\mathrm{h}) \& \mathrm{G})$. Note that additivity indicates that the probabilities associated with the engaged and disengaged states are conditional on the fixation condition, but not on target intensity. Note also that $P(\mathrm{D} \mid \mathrm{S}(). \& \mathrm{G})$ can be 1.0 and additivity still be obtained. Thus, the model can account for either unimodal or bimodal SRT distributions by an appropriate selection of the probabilities associated with the engaged and disengaged states.

\subsection{Temporal dynamics lead to predictions of superadditivity and subadditivity}

Although the effects of visual target intensity were additive with the gap effect, the auditory intensity $\times$ fixation condition produced a small but statistically significant superadditive interaction. Additive results will only be obtained in the present model if the density function for target detection times $\left(f_{\mathrm{s}}\right)$ falls entirely within the period in which the system is in the D state, which was defined above as a temporal interval extending from $\tau_{1}$ to $\tau_{1}+\tau_{2}$ following the offset of the fixation point (see Fig. 10). If a portion of the density function representing the latencies for target detection falls outside of this interval, then additivity is no longer predicted, since the condition that $P(\mathrm{D} \mid \mathrm{S}(1) \& \mathrm{G})=P(\mathrm{D} \mid \mathrm{S}(\mathrm{h}) \& \mathrm{G})$ and $P(\mathrm{E} \mid \mathrm{S}(1) \& \mathrm{G})=$ $P(\mathrm{E} \mid \mathrm{S}(\mathrm{h}) \& \mathrm{G})$ no longer holds.
Figure 10 illustrates several possible variations in the relative timing between the completion times for sensory processing $\left(f_{\mathrm{s}}\right)$ and the time-course of the $\mathrm{D}$ state. If the gap duration is brief, the early portion of the high-intensity density function precedes the onset of the $\mathrm{D}$ state. This creates a superadditive interaction (Fig. 10, 2nd row). In contrast, if the gap duration is long, target detection times are delayed relative to the timing of the D state. In this case, it is the weak signals that are less likely to be detected in the D state, and subadditive interactions are expected (Fig. 10, 4th row). Thus, the model suggests that, besides additivity of the mean contrast, both superadditive and subadditive interactions are possible: it depends upon the relationship between the latency distribution of the D state, the latency distribution for detection of the target, and the interval between the offset of the fixation point and the onset of the target. We note here that while statistically significant, the actual magnitude of the observed interaction between auditory intensity and fixation release is quite modest, which in this context may be taken to indicate that most of the density function for the auditory detection times does fall within the D state.

We are left with the interesting conclusion that, while the present results provide strong evidence of additivity (and thus seriality) between sensory processing and fixation release, the model predicts interactions when the gap duration varies. The predicted pattern moves from 'degeneraive' cases of additivity (with gap durations that are completely ineffective), through superadditivity (when the parallel processes associated with target detection and those associated with initiating fixation release 'race' one another), to additivity (at the optimal gap duration), followed at longer gap durations by subadditivity (as a greater proportion of low-intensity targets are detected after the system switches back to the E state). Finally, at very long (ineffective) gap durations, we once again expect a 'degenerative' case of additivity (since at very long gap durations, the system has always settled back into the engaged state). This set of predictions represents a powerful test of the general concepts embodied within the present model, and we are currently evaluating their accuracy.

\section{Conclusion}

Early sensory pathways are massively parallel networks, and the present results indicate how parallel auditory and visual afferent channels interact in the saccadic control system. This behavioral evidence of auditory-visual summation has a clear counterpart in the neurobiology of the superior colliculus.

It is equally clear that serial processing occurs widely in central neural systems, and we have shown how factors that promote the occurrence of express saccades operate at a stage of processing that is organized in series with the processes mediating bimodal summation. This conclusion of serial processing also appears to have a neurobiological counterpart. 
The factorial approach does more than provide a strong basis for relating theory and data in human performance. It also has the potential to provide conceptual links between human performance and the neural control systems that mediate it.

Acknowledgement. This research was supported by grant no. 89-0437 of the Office of Scientific Research, United States Air Force.

\section{Appendix}

Proof of the superadditivity of the mean contrast for models of parallel processing in the minimum completion mode (race models)

Here we present the derivation of the predicted superadditive mean contrast for the minimum completion time parallel processing model. We begin by defining $X_{1}$ and $X_{2}$ as experimental factors influencing the random times $T_{1}$ and $T_{2}$. The derivation makes no assumptions concerning the distribution of $T_{1}$ and $T_{2}$ and requires only that the levels of factors $X_{1}$ and $X_{2}$ produce reliable ordering with respect to the distribution of $T_{1}$ and $T_{2}$. In the present case, factors $X_{1}$ and $X_{2}$ represent the signal intensities of the visual and auditory targets, so we only assume a reliable intensity effect on the latency distributions. More formally, we assume that differentiating the survivor function of $T_{1}$ with respect to $X_{1}$ and differentiating the survivor function of $T_{2}$ with respect to $X_{2}$ yields negative values.

The survivor function simply tells us the proportion of trials in which the subject has not responded by time $t(\overline{\mathbf{F}}(t)=P(T>t))$. Since the mean of a positive random variable can be calculated by integrating its survivor function from 0 to $\propto$, we can express the mean contrast in terms of survivor functions as follows:

$$
\begin{aligned}
\overline{\mathrm{RT}}(0,0) & -\overline{\mathrm{RT}}(0,1)-\overline{\mathrm{RT}}(1,0)+\overline{\mathrm{RT}}(1,1) \\
& =\int_{0}^{\infty} \overline{\mathrm{F}}_{(0,0)}(t)-\overline{\mathrm{F}}_{(0,1)}(t)-\overline{\mathrm{F}}_{(1,0)}(t)+\overline{\mathrm{F}}_{(1,1)}(t) \mathrm{d} t
\end{aligned}
$$

Given the minimum completion time parallel processing model, we can write the above survivor functions as being composed of two random times $T_{1}$ and $T_{2}$. That is, for example, we can write $\overline{\mathrm{F}}_{(0,0)}(t)=\overline{\mathrm{F}}_{1(0)}(t) \times \overline{\mathrm{F}}_{2(0)}(t)$ because of the independence assumption in the minimum completion time parallel processing model. The symbol $\overline{\mathrm{F}}_{1(0)}(t)$ denotes the survivor function of the random variable $T_{1}$ when the experimental factor $X_{1}$ is at the level 0 , and $\overline{\mathrm{F}}_{2(0)}(t)$ represents the survivor function of the random variable $T_{2}$ when the experimental factor $X_{2}$ is at the level 0 . Therefore, the above can be expressed as

$$
\begin{aligned}
= & \int_{0}^{\infty} \overline{\mathrm{F}}_{1(0)}(t) \times \overline{\mathrm{F}}_{2(0)}(t)-\overline{\mathrm{F}}_{1(0)}(t) \times \overline{\mathrm{F}}_{2(1)}(t) \\
& -\overline{\mathrm{F}}_{1(1)}(t) \times \overline{\mathrm{F}}_{2(0)}(t)+\overline{\mathrm{F}}_{1(1)}(t) \times \overline{\mathrm{F}}_{2(1)}(t) \mathrm{d} t \\
= & \int_{0}^{\infty}\left\{\overline{\mathrm{F}}_{1(0)}(t)-\overline{\mathrm{F}}_{1(1)}(t)\right\} \times\left\{\overline{\mathrm{F}}_{2(0)}(t)-\overline{\mathrm{F}}_{2(1)}(t)\right\} \mathrm{d} t
\end{aligned}
$$

The above quantity is greater than zero, that is the interaction is superadditive, if we have the survivor function ordering on the random times $T_{1}$ and $T_{2}$. The survivor function ordering means that $\overline{\mathrm{F}}_{1(0)}(t)>\overline{\mathrm{F}}_{1(1)}(t)$ for $T_{1}$, and $\overline{\mathrm{F}}_{2(0)}(t)>\overline{\mathrm{F}}_{2(1)}(t)$ for $T_{2}$. Intuitively and with less rigor, the ordering of survivor functions with respect to intensity can be interpreted as higher intensity giving rise to a reduction in processing time.

\section{Appendix 2}

Proof that the magnitude of violations of the race inequality are inversely related to base time

First, let us define $\mathbb{R} I(t \mid O)$ as the magnitude of the violation of race inequality in the overlap condition at time $t$, and $\mathbb{R} \mathbb{I}(t \mid \mathrm{G})$ as the magnitude of the violation of race inequality in the gap condition at time $t$. We write the race inequality violation as follows:

$\mathbb{R} \mathbb{I}(t)=F_{\mathrm{A} \& \mathrm{~V}}(t)-F_{\mathrm{A}}(t)-F_{\mathrm{V}}(t)$

where $F_{\mathrm{A} \& \mathrm{~V}}(t)$ is the empirical cumulative distribution function $(\mathrm{CDF})$ of the bimodal condition, $F_{\mathrm{A}}(t)$ is the empirical CDF of the auditory condition, and $F_{\mathrm{V}}(t)$ is the empirical CDF of the visual condition.

Let us define two base time random variables, $T_{\mathrm{B} 1}$ and $T_{\mathrm{B} 2}$, and the corresponding CDFs as $F_{\mathrm{B} 1}(t)$ and $F_{\mathrm{B} 2}(t)$. The density functions for the two base time random variables are $f_{\mathrm{B} 1}(t)$ and $f_{\mathrm{B} 2}(t)$. Then we can write the bias of the race inequality violation given the base time random variable $T_{\mathrm{B} 1}$ as

$$
\begin{aligned}
F_{\mathrm{A} \& \mathrm{~V} \mid \mathbb{B} 1}(t)-F_{\mathrm{A} \mid \mathbb{B} 1}(t) & -F_{\mathrm{V} \mid \mathbb{B} 1}(t) \\
=F_{\mathrm{T}_{\Delta v}}(t)^{*} f_{\mathrm{T}_{\mathrm{B}_{1}}}(t) & -F_{\mathrm{T}_{A}}(t)^{*} f_{\mathrm{T}_{\mathrm{B}}}(t)-F_{\mathrm{T}_{\mathrm{v}}}(t)^{*} f_{\mathrm{T}_{\mathrm{B}} 1}(t) \\
& -F_{\mathrm{T}_{\mathrm{Av}}}(t)-F_{\mathrm{T}_{\mathrm{A}}}(t)-F_{\mathrm{T}_{\mathrm{V}}}(t)
\end{aligned}
$$

where '*' denotes the convolution operation. The cumulative distribution of the convolution of two random variables, for example, $T_{\mathrm{AV}}$ and $T_{\mathrm{B} 1}$, can be represented by $F_{\mathrm{T}_{\wedge \mathrm{v}}}(t)^{*} f_{\mathrm{T}_{\mathrm{B}_{1}}}(t)$ or equivalently $f_{\mathrm{T}_{\mathrm{Av}}}(t)^{*} F_{\mathrm{T}_{\mathrm{B} 1}}(t)$.

We next write the bias of the race inequality violation given a different base time random variable $\left(T_{\mathrm{B} 2}\right)$ as

$$
\begin{aligned}
F_{\mathrm{A} \& \mathbf{V} \mid \mathbb{B} 2}(t)-F_{\mathrm{A} \mid \mathbb{B} 2}(t) & -F_{\mathrm{V} \mid \mathbf{B} 2}(t) \\
=F_{T_{A v}}(t)^{*} f_{T_{\mathrm{B} 2}}(t) & -F_{T_{A}}(t)^{*} f_{T_{\mathrm{B} 2}}(t)-F_{T_{\mathrm{V}}}(t)^{*} f_{T_{\mathrm{B} 2}}(t) \\
& -F_{T_{\mathrm{Av}}}(t)-F_{T_{\mathrm{A}}}(t)-F_{T_{\mathrm{v}}}(t)
\end{aligned}
$$

Since we wish to compare the size of the violations given $T_{\mathrm{B} 1}$ and $T_{\mathrm{B} 2}$, we subtract

$F_{\mathrm{A} \& \mathrm{~V} \mid \mathrm{B} 2}(t)-F_{\mathrm{A} \mid \mathbf{B} 2}(t)-F_{\mathrm{V} \mid \mathbf{B} 2}(t) \quad$ from $\quad F_{\mathrm{A} \& \mathrm{~V} \mid \mathbb{B} 1}(t)-$ $F_{\mathrm{A} \mid \mathbb{B} 1}(t)-F_{\mathrm{V} \mid \mathbb{B} 1}(t)$, which yields

$$
\begin{aligned}
& F_{\mathrm{A} \& \mathrm{~V} \mid \mathbb{B} 1}(t)-F_{\mathrm{A} \mid \mathrm{B} 1}(t)-F_{\mathrm{V} \mid \mathrm{B} 1}(t) \\
& -F_{\mathrm{A \& V} \mid \mathbb{B} 2}(t)+F_{\mathrm{A} \mid \mathbb{B} 2}(t)+F_{\mathrm{V} \mid \mathbb{B} 2}(t) \\
& =F_{T_{\wedge \mathrm{V}}}(t)^{*}\left(f_{T_{\mathrm{B} 1}}(t)-f_{T_{\mathrm{B} 2}}(t)\right)-F_{T_{\wedge}}(t)^{*}\left(f_{T_{\mathrm{H}_{1}}}(t)\right. \\
& \left.-f_{T_{\mathrm{B} 2}}(t)\right)-F_{T_{v}}(t)^{*}\left(f_{T_{\mathrm{B} 1}}(t)-f_{T_{\mathrm{B} 2}}(t)\right) \\
& =f_{T_{A v}}(t)^{*}\left(F_{T_{\mathrm{w}_{1}}}(t)-F_{T_{\mathrm{w}_{2}}}(t)\right)-f_{T_{\mathrm{A}}}(t)^{*}\left(F_{T_{\mathrm{B} 1}}(t)\right. \\
& \left.-F_{T_{\mathrm{B}_{2}}}(t)\right)-f_{T_{\mathrm{v}}}(t)^{*}\left(F_{T_{\mathrm{B}_{1}}}(t)-F_{T_{\mathrm{B} 2}}(t)\right) \\
& =\left(f_{T_{A v}}(t)-f_{T_{1}}(t)-f_{T_{\mathrm{v}}}(t)\right)^{*}\left(F_{T_{\mathrm{B} 1}}(t)-F_{T_{\mathrm{B} 2}}(t)\right)
\end{aligned}
$$


Neural summation between the auditory and visual channels implies $\left(F_{T_{\mathrm{Av}}}(t)-F_{T_{\mathrm{A}}}(t)-F_{T_{\mathrm{V}}}(t)\right)>0$ for some $t$ (Townsend and Nozawa, 1994 unpublished data). Since $\left(F_{T_{A v}}(t)-F_{T_{A}}(t)-F_{T_{v}}(t)\right)>0$, there exists an interval $(0, t)$ such that $\left(f_{T_{\mathrm{Av}}}(t)-f_{T_{\mathrm{A}}}(t)-f_{T_{\mathrm{v}}}(t)\right)>0$ is true.

If we have $F_{T_{B_{1}}}(t)>F_{T_{B_{2}}}(t)$ (base time 1 is faster than base time 2), then we have a positive value for $\left(f_{T_{\mathrm{AV}}}(t)-f_{T_{\mathrm{A}}}(t)-f_{T_{\mathrm{v}}}(t)\right)^{*}\left(F_{T_{\mathrm{B} 1}}(t)-F_{T_{\mathrm{B} 2}}(t)\right)$. That is, if base time 1 is faster than base time 2 , then the difference in the magnitude of the race inequality violation is positive. This positive difference means that the violations are smaller with longer base times.

\section{References}

Bishop PO, Levick WR, Williams WO (1964) Statistical discharge of lateral geniculate neurons. J Physiol 170:598-612

Boch R, Fischer B (1983) Saccadic reaction times and activation of prelunate cortex: parallel observation in trained rhesus monkeys. Exp Brain Res 50:201-210

Coleman R, Gastwirth JL (1969) Some models for interaction of renewal processes related to neuron firing. J Appl Probab $6: 38-58$

Colonius H (1990) Possibly dependent probability summation of reaction time J Math Psychol 34:253-275

Donders FC (1869) Over de snelheid van psychische processes. Orderzoekingon gedaan in het Psychologish Laboratorium der Utrechtshe Hoogeschool, 1868-1869, Tweedereeks, II, 92-120. Translated by WG Koster in: Koster WG (ed) Attention and performance, II Acta Psychol 30:412-431

Dudewicz EJ (1976) Introduction to statistics and probability. Holt, Rinehart \& Winston, New York

Fendrich R, Hughes HC, Reuter-Lorenz PA (1991) Fixation point offsets reduce the latency of saccades to acoustic targets. Percept Psychophys 50:383-387

Fischer B (1987) The preparation of visual guided saccades. Rev Physiol Biochem Pharmacol 106:2-35

Fischer B, Boch R (1983) Saccadic eye movements after extremely short reaction times in the monkey. Brain Res 260:21-26

Fischer B, Ramsperger E (1984) Human express saccades: extremely short reaction times of goal directed eye movements. Exp Brain Res 57:191-195

Fischer B, Ramsperger E (1986) Human express-saccades: effect of daily practice and randomization. Exp Brain Res 64:569-578.

Fischer B, Rogal L (1986a) Eye-hand-coordination in man: a reaction time study. Biol Cybern 55:253-261

Fischer B, Rogal L (1986b) Eye-hand-coordination: a model for computing reaction times in a visually guided reach task. Biol Cybern $55: 263-273$

Fischer B, Weber H (1993) Express saccades and visual attention. Behav Brain Sci 16:553-610

Goldberg ME, Bushnell MC, Bruce CJ (1986) The effect of attentive fixation on eye movements evoked by electrical simulation of the frontal eye fields. Exp Brain Res 61:579-584

Hallet PE (1978) Primary and secondary saccades to goals defined by instructions. Vision Res 18:1279-1286

Harris CM, Hainline L, Abramov I, Lemerise E, Camenzuli C (1988) The distribution of fixation durations in infants and naive adults. Vision Res 28:419 432

Hughes HC, Kelsey JV (1984) Response-dependent effects on near threshold detection performance: saccades versus manual responses. Percept Psychophys 35:543-546

Hughes HC, Reuter-Lorenz PA, Nozawa G, Fendrich R (1994) Bimodal interactions in sensory-motor processing: saccades versus manual responses. J Exp Psychol Human Percept Perform 20:131-153

Iwasaki S (1990) Facilitation of reaction times with GAP paradigm: comparison of manual and saccadic responses. Ergonomics $13: 833-850$
Jay MF, Sparks DL (1987) Sensorimotor integration in the primate superior colliculus II. Coordinates of auditory signals. J Neurophysiol 57:35-55

Jay MF, Sparks DL (1990) Localization of auditory and visual target for the initiation of saccadic eye movements. In: Berkley MA, Stebbins W (eds) Comparative perception, Vol I. Basic mechanisms. Wiley, New York

Juttner M, Wolf W (1994) Stimulus sequence effects on human described by a Markov model. Biol Cybern 70 (in press)

Kingstone A, Klein RM (1993a) Why do visual offsets reduce saccodic latencies? Behav Brain Sci 16:583-584

Kingstone A, Klein RM (1993b) What are human express saccades Psychophys (in press)

Mayfrank L, Mobashery M, Kimmig H, Fischer B (1986) The role of fixation and visual attention in the occurrence of express saccades in man. Eur Arch Psychiatry Neurol Sci 235:269-275

Meredith MA, Stein BE (1983) Interactions among converging sensory inputs in the superior colliculus. Science 221:389-391

Miller JO (1982) Divided attention: evidence for coactivation with redundant signals. Cogn Psychol 14:247-279

Miller JO (1986) Time course of coactivation in bimodal divided attention. Percept Psychophys 40:331--343

Nozawa G (1989) A study of redundant target processing: evidence for parallel processing. Master's thesis, Purdue University, West Layfayette

Nozawa $G$ (1992) Stochastic models of human information processing. Doctoral dissertation, Dartmouth College, Hanover

Peck CK (1987) Auditory interactions in cat's superior colliculus: their role in the control of gaze. Brain Res 420:162-166

Pooi AH, Lee PA (1975) An interaction model of a poisson and renewal process related to a neural firing. Biol Cyber 17:71-76

Raab D (1962) Statistical facilitation of simple reaction times. Trans NY Acad Sci 24:574-590

Reulen JPH (1984a) Latency of visually evoked saccadic eye movements. I Saccadic latency and the facilitation model. Biol Cybern $50: 251-262$

Reulen JPH (1984b) Latency of visually evoked saccadic eye movements II. Temporal propertics of the facilitation mechanism. Biol Cybern 50:263-271

Reuter-Lorenz PA, Hughes HC (1993) Warning signals, response specificity and the gap effect: implications for a non-attentional account. Behav Brain Sci 16:585-586

Reuter-Lorenz PA, Hughes HC, Fendrich R (1991) The reduction of saccadic latency by prior offset of the fixation point: an analysis of the 'gap effect'. Percept Psychophys 49:165-176

Reuter-Lorenz PA, Oonk H, Barnes L, Hughes HC (1993) Response specificity of the gap effect depends on the presence of a warning signal. Exp Brain Res (in press)

Robinson DA (1972) Eye movements evoked by collicular stimulation in the alert monkey. Vis Res 12:1795-1808

Rohrer WH, Sparks DL (1986) Role of the superior colliculus in the initiation of express saccades. Invest Ophthalmol Vis Sci 27:156 (abstract)

Saslow MG (1967) Effects of components of displacement-step stimuli upon latency of saccadic eye movement. J Opt Soc Am 57: 1024-1029

Stein B, Meredith MA (1990) Multisensory integration. Neural and behavioral solutions for dealing with stimuli different sensory modalities. In: The development and neural bases of higher cognitive functions, Annals of the New York Academy of Sciences (608)

Sternberg S (1969) The discovery of processing stages: extensions of Donders' method. In: Koster WG (ed) Attention and performance II North Holland, Amsterdam, pp 276-315

Teichner WH, Krebs MJ (1972) Laws of the simple visual reaction time. Psychol Rev 79:344-358

Ten Hoopen M, Reuver HA (1965) Selective interaction of two independent recurrent processes. J Appl Probab 2:286 292

Titterington DM, Smith AFM, Makov UE (1985) Statistical analysis of finite mixture distributions Wiley, Chichester

Townsend JT (1984) Uncovering mental processes with factorial experiments. J Math Psychol 28:363-400

Townsend JT, Ashby FG (1983) Stochastic modeling of elementary psychological processes. Cambridge University Press, Cambridge 
Townsend JT, Piotrowski SM (1981) Parallel systems and factorial additivity of mean reaction time. Paper presented at Psychonomic Society Meeting, Philadelphia

Wenban-Smith M, Findlay J (1991) Express saccades: it there a separate population in humans? Exp Brain Res 87:218-222

Westendorf D, Blake R (1988) Binocular reaction times to contrast increments. Vis Res 28:355-359
Wheeless LL, Cohen GH, Boynton RM (1967) Luminance as a parameter of the eye movement control system. J Opt Soc Am $57: 394-400$

Wolpole RE, Myers RH (1972) Probability and statistics for engineers and scientists. MacMillan, New York

Wurtz RH, Albano JE (1980) Visuo-motor function of the primate superior colliculus. Ann Rev Neurosci 31:189-220 